\title{
Tissue-specific GATA factors are transcriptional effectors of the small GTPase RhoA
}

\author{
Frédéric Charron, ${ }^{1,2}$ George Tsimiklis, ${ }^{1,2}$ Mathieu Arcand, ${ }^{3,4}$ Lynda Robitaille, ${ }^{1}$ Qiangrong Liang, ${ }^{5}$ \\ Jeffery D. Molkentin, ${ }^{5}$ Sylvain Meloche, ${ }^{3,4}$ and Mona Nemer ${ }^{1,2,3,6}$ \\ ${ }^{1}$ Laboratoire de développement et différenciation cardiaques, Institut de recherches cliniques de Montréal (IRCM), Montréal, \\ Québec, Canada H2W 1R7; ${ }^{2}$ Department of Medicine, Division of Experimental Medicine, McGill University, Montréal, \\ Québec H3A 1A3, Canada; ${ }^{3}$ Département de pharmacologie, Université de Montréal, Montréal, Québec H3C 1AC, Canada; \\ ${ }^{4}$ Laboratoire de signalisation et croissance cellulaire, IRCM, Montréal, Québec, Canada H2W 1R7; ${ }^{5}$ Department of \\ Pediatrics, Children's Hospital Medical Center, Cincinnati, Ohio 45229, USA
}

\begin{abstract}
Rho-like GTPases play a pivotal role in the orchestration of changes in the actin cytoskeleton in response to receptor stimulation, and have been implicated in transcriptional activation, cell growth regulation, and oncogenic transformation. Recently, a role for RhoA in the regulation of cardiac contractility and hypertrophic cardiomyocyte growth has been suggested but the mechanisms underlying RhoA function in the heart remain undefined. We now report that transcription factor GATA-4, a key regulator of cardiac genes, is a nuclear mediator of RhoA signaling and is involved in the control of sarcomere assembly in cardiomyocytes. Both RhoA and GATA-4 are essential for sarcomeric reorganization in response to hypertrophic growth stimuli and overexpression of either protein is sufficient to induce sarcomeric reorganization. Consistent with convergence of RhoA and GATA signaling, RhoA potentiates the transcriptional activity of GATA-4 via a p38

MAPK-dependent pathway that phosphorylates GATA-4 activation domains and GATA binding sites mediate RhoA activation of target cardiac promoters. Moreover, a dominant-negative GATA-4 protein abolishes RhoA-induced sarcomere reorganization. The identification of transcription factor GATA-4 as a RhoA mediator in sarcomere reorganization and cardiac gene regulation provides a link between RhoA effects on transcription and cell remodeling.
\end{abstract}

[Key Words: RhoA; GATA-4; p38 MAPK; heart; cell signaling; transcription]

Received May 31, 2001; revised version accepted August 30, 2001.

Sarcomeres are the contractile units of the heart. They are composed of highly organized actin and myosin filaments, stabilized by $\alpha$-actinin. Other muscle-specific proteins such as troponins and tropomyosins also compose the contractile filaments and are involved in regulating contraction (Seidman and Seidman 2001). Altered sarcomere assembly or function profoundly influences cardiac function as best exemplified by human cardiomyopathies, which result from mutation of any one of the sarcomeric proteins (Kamisago et al. 2000; Seidman and Seidman 2001). Cardiac development and cardiac hypertrophy-the growth response of terminally differentiated cardiomyocytes-are associated with major changes in contractile protein gene expression and sarcomeric organization, which in turn regulate heart function. Cardioregulatory hormones and neurotransmitters that act

${ }^{6}$ Corresponding author.

E-MAIL nemerm@ircm.qc.ca; FAX (514) 987-5575.

Article and publication are at http://www.genesdev.org/cgi/doi/10.1101/ gad. 915701 . through G protein-coupled receptors-like adrenergic agonists and vasoactive peptides-also alter cardiomyocyte size, contractility, and sarcomeric protein gene expression and are implicated in the pathogenesis of human cardiac dysfunction and heart failure (Hunter and Chien 1999). At present the mechanisms and transcription factors involved in regulating cardiac genes and sarcomere organization during normal or pathologic cardiac growth are not fully understood.

Members of the Rho family of small GTPases are key regulators that link membrane receptors to cytoskeletal organization and gene transcription thereby affecting diverse biological responses including cell shape and proliferation. Although many downstream effectors of Rho GTPases have been identified (Bar-Sagi and Hall 2000), the transcription factors that mediate Rho-dependent changes in gene expression remain essentially unknown. In fact, few Rho target genes have been analyzed and only a handful of transcription factors have been shown to be regulated by Rho GTPases. These include NFKB, $\mathrm{AP}-1$, and the serum response factor (SRF). The best- 
studied transcription target of Rho is the c-fos promoter, which is activated by RhoA through the serum response element (SRE) (Hill et al. 1995). The exact mechanism by which RhoA regulates SRE function is not well understood, but it does not appear to involve direct modulation of either SRF or its associated ternary complex (TCF) (Hill et al. 1995). Rather, it has been suggested that RhoA activation leads to recruitment by DNA-bound SRF of an as-yet-unidentified accessory factor (Treisman et al. 1998). RhoA has also been shown to potentiate phorbol ester activation of AP-1 elements through association with and activation of PKC $\alpha$ (Chang et al. 1998). Finally, RhoA enhances ІкB phosphorylation leading to its dissociation from $\mathrm{NF}_{\mathrm{B}}$; this, in turn, promotes the nuclear translocation and transcriptional effects of $\mathrm{NF} \kappa \mathrm{B}$ (Perona et al. 1997). Whether any of these transcription factors is involved in RhoA-dependent alteration of normal or abnormal cell growth is not clear; effector domain mutants of RhoA suggest dissociation of SRE activation, cytoskeletal reorganization, and cellular transformation (Sahai et al. 1998; Zohar et al. 1998).

In cardiomyocytes, overexpression of RhoA induces sarcomere reorganization (Hoshijima et al. 1998) and contractile dysfunction (Sah et al. 1999); it also up-regulates the atrial natriuretic factor (ANF) gene (Sah et al. 1996; Hoshijima et al. 1998), which represents a hallmark of the genetic reprogramming in cardiac hypertrophy. RhoA (but not RhoB) is expressed in cardiomyocytes, and treatment with a hypertrophic growth factor (angiotensin II) was shown to induce RhoA translocation to the cell membrane (Aoki et al. 1998). Although these studies support a role for RhoA in cardiomyocyte hypertrophy, the exact role of RhoA in mediating sarcomeric reorganization in response to hypertrophic stimuli remains controversial (Thorburn et al. 1997; Hoshijima et al. 1998). There is, however, general agreement for an involvement of RhoA in the transcriptional changes observed in hypertrophy; two inhibitors of Rho function, the C3 transferase and the dominant-negative RhoA N19 protein, were shown to inhibit $\alpha 1$-adrenergic stimulation of ANF transcription (Sah et al. 1996; Thorburn et al. 1997), and the selective Rho-kinase inhibitor Y27632 was recently reported to block endothelin-1 (Et-1) induction of the ANF promoter (Kuwahara et al. 1999). Interestingly, although the ANF promoter contains both AP-1 and SRE elements (McBride and Nemer 1998; Morin et al. 2001), neither was required to mediate the inhibitory effect of Y27632 (Kuwahara et al. 1999); and whereas C3 transferase inhibited $\alpha 1$-adrenergic activation of the ANF promoter, it did not affect that of an AP-1 dependent reporter (Thorburn et al. 1997). This suggests that Rho regulation of cardiac transcription is independent of AP-1 or SRE activation. However, the effectors of RhoA in cardiomyocytes remain undefined (Clerk and Sugden 2000).

The cardiac-enriched transcription factor GATA-4 recently has been implicated in transcriptional regulation of the ANF promoter in response to hypertrophic stimulation by Et-1 (Morin et al. 2001). GATA-4 is a key regulator of cardiac genes including many contractile protein genes (Charron and Nemer 1999; Charron et al. 1999). Moreover, GATA binding sites are required for in vivo activation of cardiac promoters during cardiac hypertrophy (Hasegawa et al. 1997; Herzig et al. 1997; Morimoto et al. 2000). In this paper, we report that GATA-4 is a transcriptional effector of RhoA in cardiomyocytes and is involved in sarcomere assembly. We show that RhoA potentiates GATA-4 transcriptional activity both on isolated GATA elements and on cardiac promoters known to be GATA targets. Potentiation of GATA-4 activity results from RhoA enhancement of its $\mathrm{N}$ - and C-terminal domains and involves p38 MAPK-dependent phosphorylation and activation of these transactivation domains. Together, these results identify for the first time a transcription factor that controls sarcomere reorganization and suggest that RhoA, in addition to its direct effect on myofibrillar assembly, could regulate cardiac transcription including sarcomeric protein gene expression by modulating the transcriptional activity of tissuespecific transcription factors.

\section{Results}

GATA-4 is essential for cardiomyocyte sarcomere reorganization

It has been shown previously that GATA-4 regulates the expression of many contractile proteins, such as $\alpha$-myosin heavy-chain, $\beta$-myosin heavy-chain, and cardiac troponin I in cardiomyocytes (Charron et al. 1999) and activates the promoter of several contractile protein genes, such as cardiac troponin $\mathrm{C}$, slow myosin heavy-chain, and cardiac $\alpha$-actin, alone or in combination with other transcription factors (Ip et al. 1994; Molkentin et al. 1994; Murphy et al. 1997; Sepulveda et al. 1998; G.F. Wang et al. 1998; Morin et al. 2000). This suggested that GATA-4 could be important for sarcomere formation in cardiomyocytes. To test this possibility, we have used neonatal cardiomyocyte cultures, where sarcomere reorganization can be induced by the hypertrophic stimuli Et-1 and phenylephrine (Phe, an $\alpha_{1}$-adrenergic agonist) as observed by the appearance of striated acto-myosin fibers upon phalloidin staining (Fig. 1a). Because GATA-4 null mice are embryonic lethal (Kuo et al. 1997; Molkentin et al. 1997), they are not amenable to study the role of GATA-4 in cardiomyocyte sarcomere reorganization. We have therefore used an adenovirus expressing an antisense GATA-4 cDNA (AS GATA-4) to specifically down-regulate GATA-4 in postnatal cardiomyocyte cultures. In these cells, GATA-4 protein levels are specifically decreased by $80 \%$ (Fig. 1b) as reported previously (Charron et al. 1999). Down-regulation of GATA-4 in cardiomyocytes blocked sarcomere reorganization induced by Et-1 and Phe, whereas a control adenovirus expressing a nls-lacZ cDNA (lacZ) had no effect on sarcomere reorganization (Fig. 1a). Quantification of reorganized cardiomyocytes showed that although Et-1 and Phe induced, respectively, a 3.2- and 4.0-fold increase in the number of cardiomyocytes that underwent sarcomere reorganization, this effect was almost abolished 
Charron et al.

a
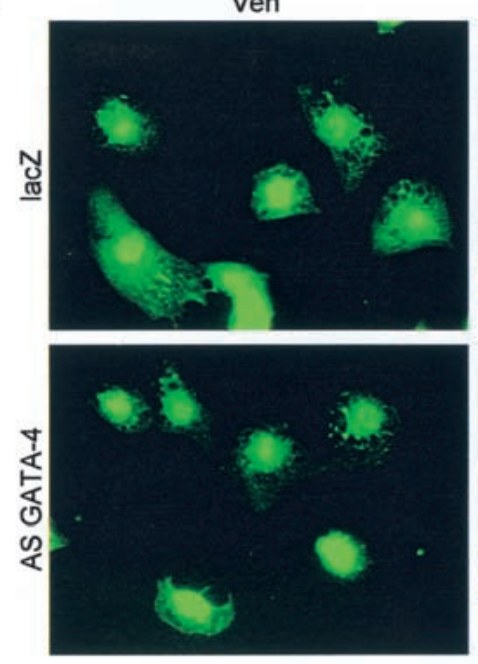

b

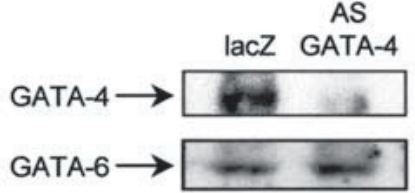

Et-1
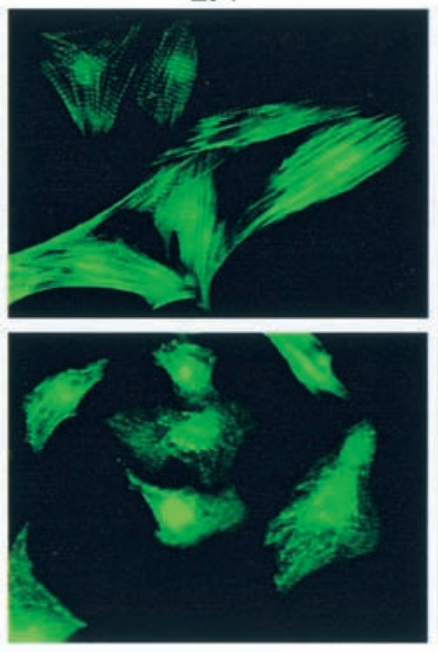

Phe
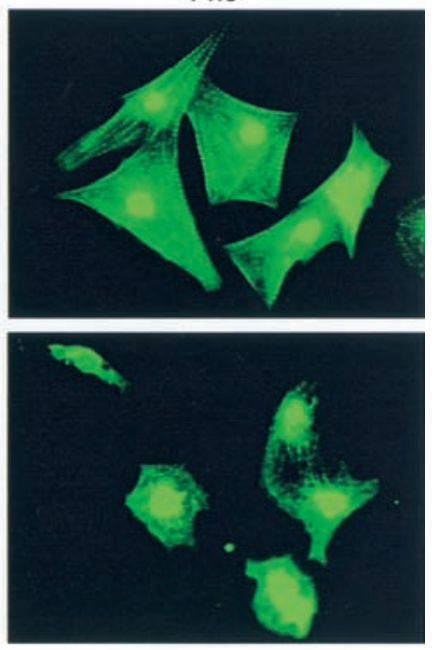

C

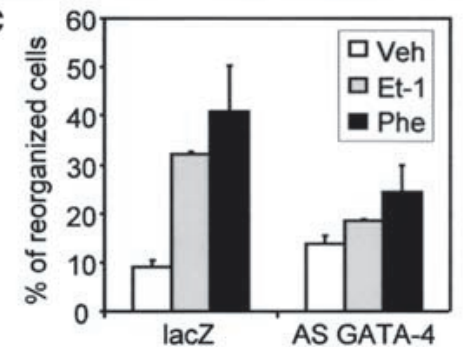

Figure 1. GATA-4 is essential for Et-1 and Phe-induced cardiomyocyte sarcomere reorganization. (a) Cardiomyocytes infected with a lacZ control adenovirus (lacZ) or with the antisense GATA-4 adenovirus (AS GATA-4) were stimulated for $48 \mathrm{~h}$ with vehicle (Veh), Et-1, or Phe. Cardiomyocytes were fixed and actin filaments were revealed using phalloidin-FITC. (b) Western blot analysis of GATA-4 protein confirming that the GATA-4 antisense adenovirus specifically decreases GATA-4 protein levels. $(c)$ Quantification of the percentage of reorganized cardiomyocytes. Cells were scored as described in Materials and Methods. The data are the average of two independent experiments.

(1.3- and 1.6-fold, respectively) in cardiomyocytes where GATA-4 expression was down-regulated (Fig. 1c).

To test the effect of enhanced GATA-4 activity, cardiomyocytes were infected with an adenovirus expressing the GATA-4 cDNA. This led to significantly increased GATA-4 protein levels and GATA-4 DNA binding activity as assessed by Western blot, immunofluorescence, and gel shift analyses (Fig. 2a,b,d). This was accompanied by up-regulation of several GATA-4 target genes including B-type natriuretic peptide (BNP) and $\alpha$-skeletal actin ( $\alpha$-SA) (Fig. 2c). Remarkably, overexpression of GATA-4 was sufficient to induce sarcomere reorganization (Fig. 2d) as efficiently as Et-1 or Phe (Fig. $2 \mathrm{e})$. Together, these results indicate that GATA-4 is an essential mediator of Et-1- and Phe-induced cardiomyocyte sarcomere reorganization and that up-regulation of GATA-4 enhances cardiac gene expression and induces cardiomyocyte sarcomere reorganization.

\section{RhoA is required for Et-1- and Phe-induced sarcomere reorganization}

The small GTPase family member RhoA is known to govern the assembly of cytoskeletal actin fibers in sev- eral cell types (Hall 1998). However, conflicting results have been obtained regarding its role in cardiomyocyte sarcomere reorganization in response to hypertrophic stimuli (Thorburn et al. 1997; Hoshijima et al. 1998). Therefore, we decided to test the role of RhoA in cardiomyocyte sarcomere reorganization and its effect, if any, on the transcription factor GATA-4.

Using a recently developed assay specific for GTPbound cellular Rho (Ren et al. 1999), we determined that cardiomyocyte stimulation with Phe increases GTP loading of Rho in a time-dependent manner (Fig. 3a), raising the possibility that enhanced Rho activity may mediate Phe-induced sarcomeric reorganization. Consistent with this idea, cardiomyocytes transfected with a constitutively active form of RhoA (RhoA V14) underwent sarcomere reorganization (Fig. $3 \mathrm{~b}$ ). To directly test the involvement of RhoA in Phe-induced cardiomyocyte sarcomere reorganization, a dominant-negative form of RhoA (RhoA N19) was transfected in cardiomyocytes stimulated with Phe. Interestingly, RhoA N19 inhibited Phe-induced sarcomere reorganization, whereas the wild-type form of RhoA (RhoA WT) did not (Fig. 3c). These results strongly support an essential role for RhoA as a mediator of Et-1- and Phe-induced cardiomyocyte 
a

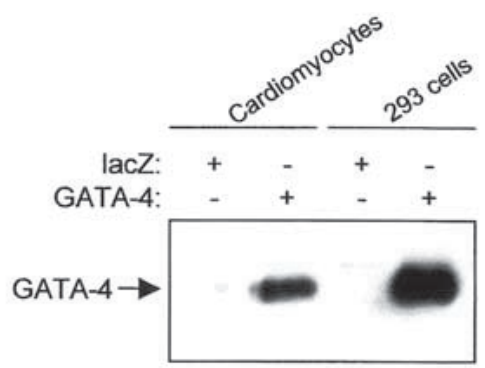

C

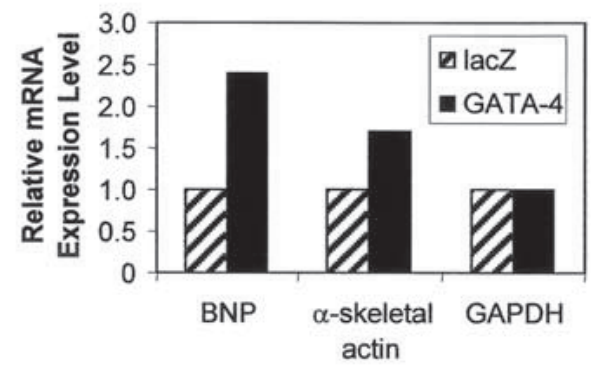

b
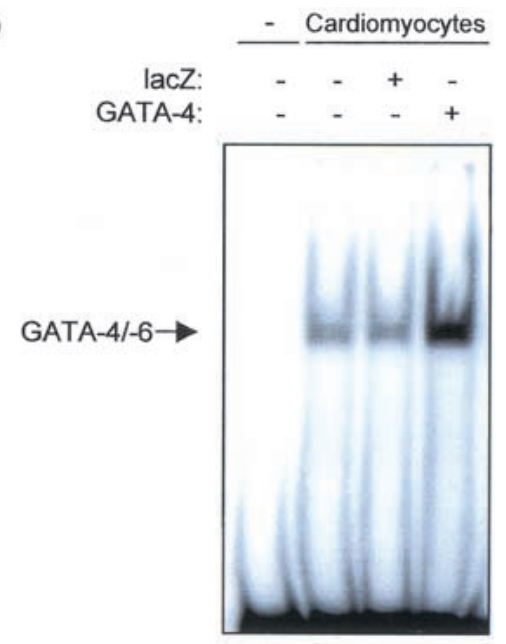

d
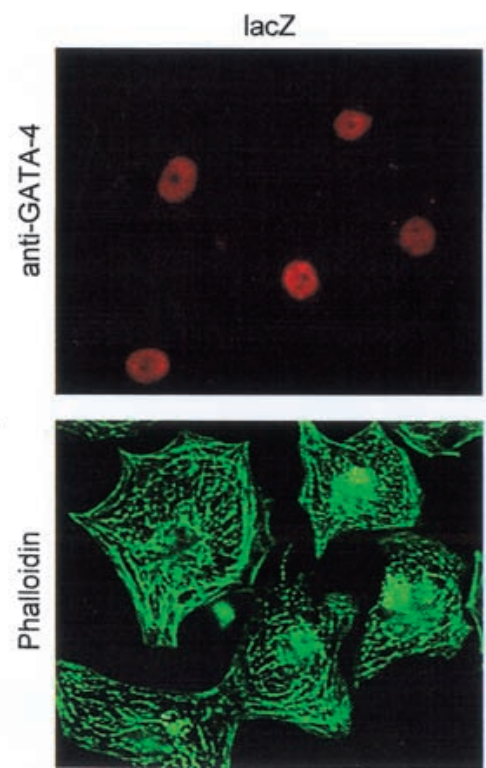
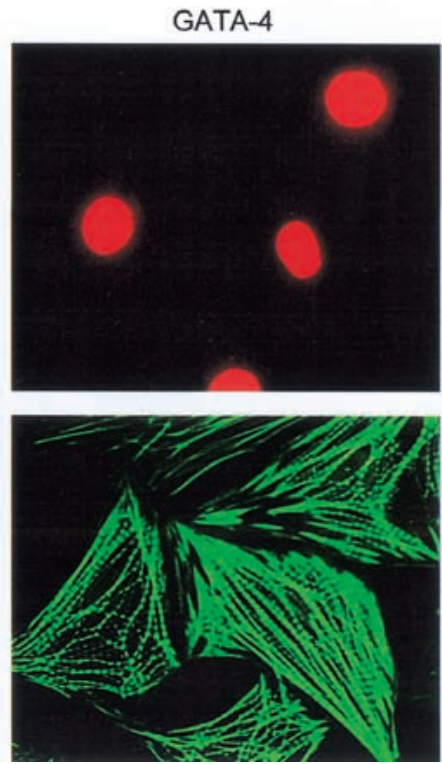

e

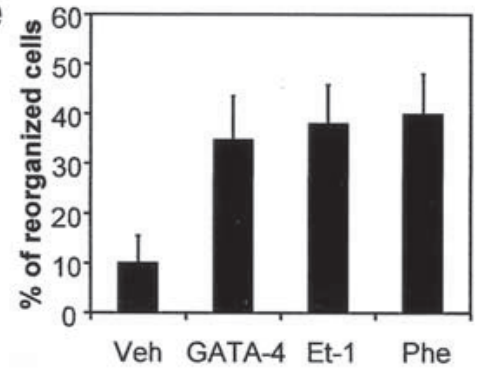

Figure 2. Up-regulation of GATA-4 activity induces contractile protein gene expression and sarcomere reorganization in cardiomyocytes. (a) Western blot analysis of nuclear extracts from cardiomyocytes and 293 cells infected with a lacZ control or with GATA4-expressing adenovirus. (b) Increased GATA DNA-binding activity in cardiomyocytes infected with the GATA-4 adenovirus. EMSAs were performed using nuclear extracts from cardiomyocytes infected with lacZ or GATA-4 adenovirus and the ANF -120-bp GATA probe. (c) Overexpression of GATA-4 induces cardiac gene expression. Total RNA (20 $\mu \mathrm{g})$ extracted from cardiomyocytes infected with lacZ or GATA-4 adenovirus was analyzed by Northern blot and quantified by PhosphorImager, as described in Materials and Methods. (d) Up-regulation of GATA-4 activity induces cardiomyocyte sarcomere reorganization. Cardiomyocytes infected with lacZ or GATA-4 adenovirus were fixed and costained using phalloidin-FITC (green) and anti-GATA-4 antibody (red). (e) Quantification of the percentage of reorganized cardiomyocytes. Cells were scored as described in Material and Methods.

sarcomere reorganization and suggest that GATA-4 and RhoA may act in the same signaling pathway.

\section{RhoA potentiates GATA-4 transcriptional activity}

To test whether GATA-4 could modulate RhoA activity, the amount of active (GTP-loaded) RhoA was determined in cardiomyocytes where GATA-4 activity was down- or up-regulated. Altering the levels of GATA-4 had no effect on RhoA activity (Fig. 4a), suggesting that GATA-4 does not regulate RhoA activity. Thus, if RhoA and GATA-4 are in the same signaling pathway, GATA-4 would lie downstream of RhoA.

To determine if this is indeed the case, we tested whether RhoA effect on sarcomere formation is GATA dependent. As shown in Figure 4b, the ability of RhoA 
a

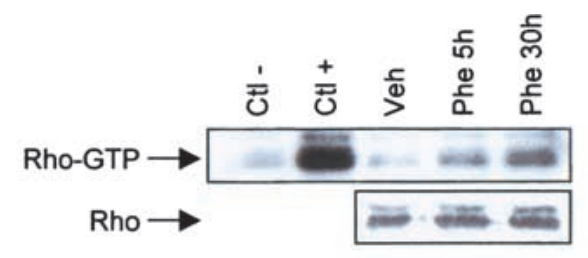

b
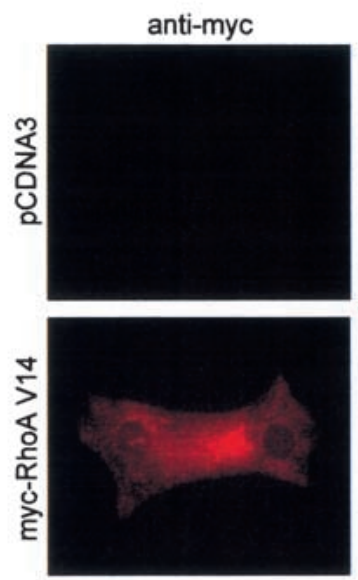

C

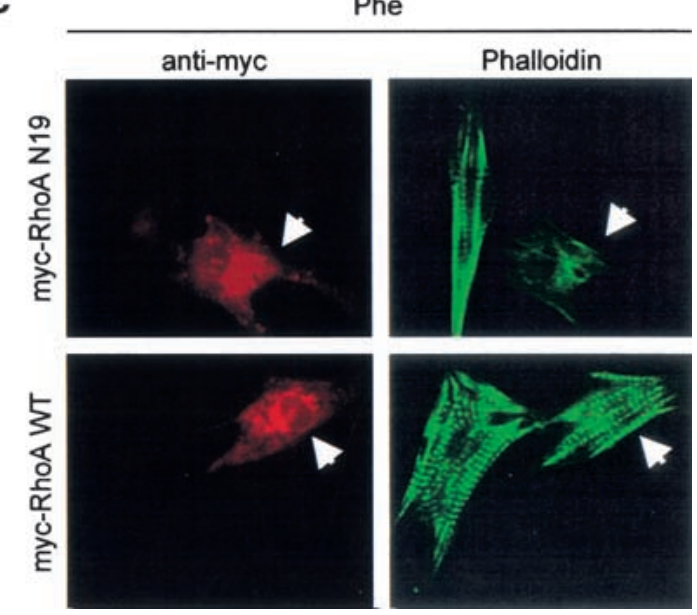

Figure 3. RhoA is required for Et-1- and Phe-induced cardiomyocyte sarcomere reorganization. (a) Phe induces Rho activity in a time-dependent manner. Whole-cell extracts were prepared from cardiomyocytes stimulated with Phe for 5 and $30 \mathrm{~h}$. The active form of Rho (Rho-GTP) was selectively affinity-precipitated using a GST-Rhotekin protein and revealed using antiRho antibody. Extracts were incubated in presence of an excess of GDP (Ctl-) or GTP- $\gamma-\mathrm{S}(\mathrm{Ctl}+)$ as negative and positive controls, respectively. The panel below shows total RhoA protein level as assessed by Western blot analysis. (b) RhoA V14 induces sarcomere reorganization in cardiomyocytes. Cardiomyocytes transfected with $2 \mu \mathrm{g}$ of pCDNA3 or pCDNA3-myc-RhoA V14 were fixed and costained using phalloidin-FITC (green) and antimyc antibody (red). (c) RhoA N19, but not RhoA WT, inhibits Phe-induced cardiomyocyte sarcomere reorganization. Cardiomyocytes transfected with $2 \mu \mathrm{g}$ of pCDNA3-myc-RhoA WT or pCDNA3-myc-RhoA N19 were stimulated for $48 \mathrm{~h}$ with Phe, fixed, and costained using phalloidin-FITC (green) and anti-myc antibody (red). The arrow indicates myc-positive cardiomyocytes. a

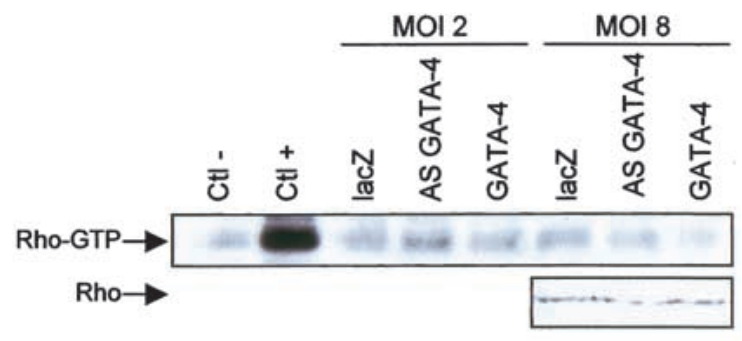

b

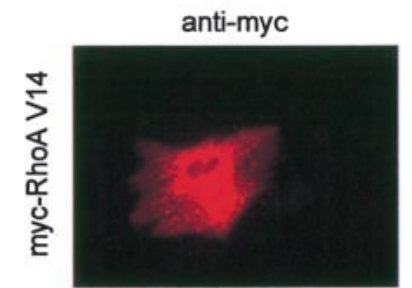

Phalloidin + anti-HA
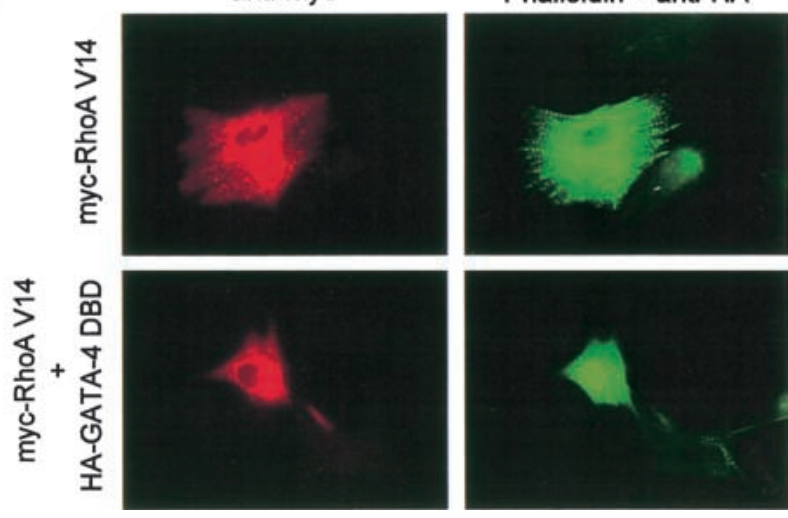

Figure 4. (a) Overexpression or down-regulation of GATA-4 does not affect RhoA activity in cardiomyocytes. Cardiomyocytes were infected with lacZ, AS GATA-4, or GATA-4 adenovirus, at MOIs of 2 or 8 , for $48 \mathrm{~h}$. Rho activity was assessed as described in Figure 3a. Extracts were incubated in presence of an excess of GDP (Ctl-) or GTP- $\gamma-\mathrm{S}(\mathrm{Ctl}+)$ as negative and positive controls, respectively. The panel below is from a Western blot showing the level of total RhoA protein in the extracts. $(b)$ GATA-4 activity is required for RhoA-induced sarcomeric reorganization. Cardiomyocytes were transiently transfected with myc-RhoA V14 in presence or absence of an expression vector encoding a HA-tagged dominant-negative GATA-4 protein lacking transcriptional activation domain (HA-GATA-4 DBD). Cells were fixed and costained with anti-myc antibody (red), anti-HA (nuclear green staining), and phalloidin-FITC (cytoplasmic green staining). Note how the presence of the GATA-4 DBD abolishes the effects of RhoA on cell size and sarcomeric reorganization.

V14 to induce sarcomere reorganization was abolished by a dominant-negative form of GATA-4 (GATA-4 DBD) consisting of the DNA-binding domain but lacking both $\mathrm{N}$ - and C-terminal transactivation domains (Durocher et al. 1997). This result is consistent with a role for GATA-4 as an essential nuclear mediator of RhoA. Because overexpression of GATA-4 can mimic RhoA effects, RhoA action likely involves up-regulation of GATA-4 expression and/or activity. Therefore, we examined the effect of RhoA on GATA-4. Cardiomyocyte transfection with RhoA V14 did not affect endogenous GATA-4 protein level or subcellular localization (Fig. 5a). The ability of RhoA to regulate GATA-4 transcriptional activity was also assessed. To this end, we cotransfected GATA-4 with RhoA V14 and tested whether RhoA V14 is able to potentiate GATA-4 transcriptional activity in serum-starved NIH $3 \mathrm{~T} 3$ cells, which do not express GATA factors (F. Charron, G. Nemer, and M. 


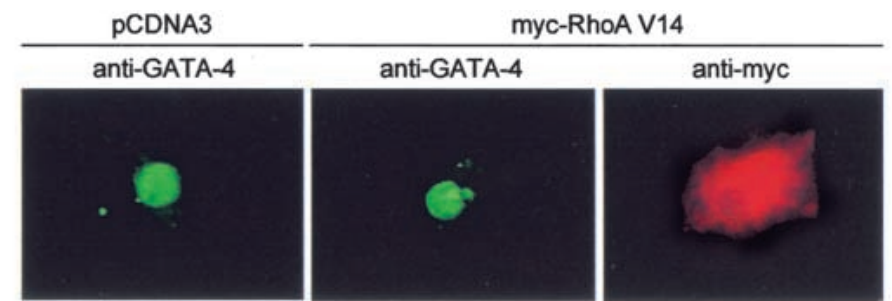

b

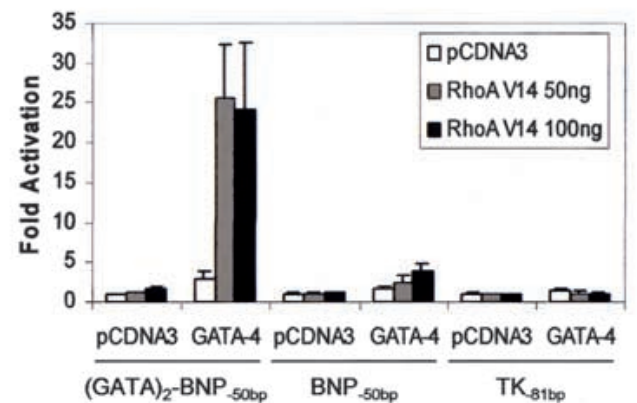

C

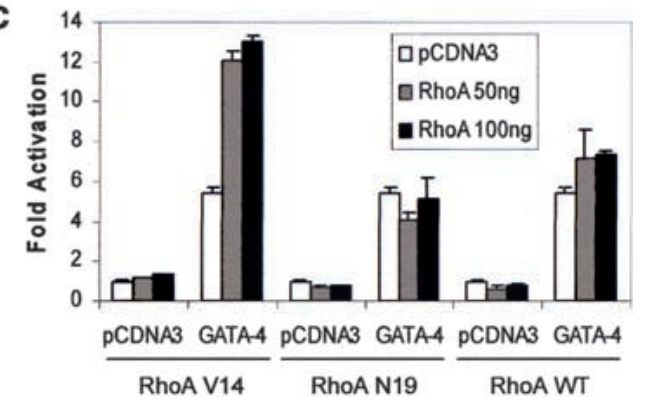

d

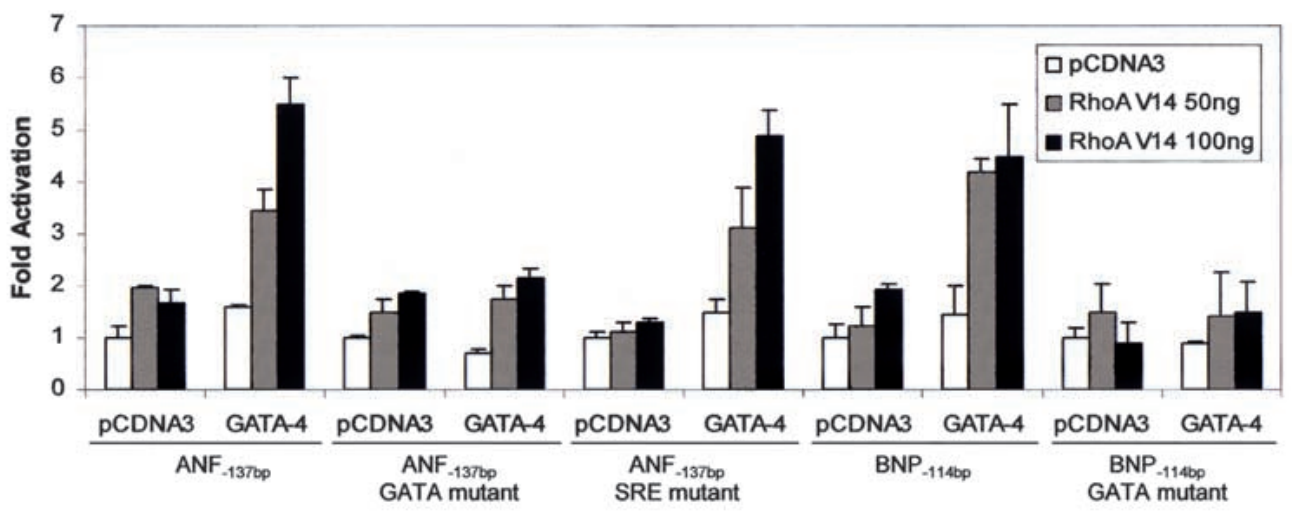

e
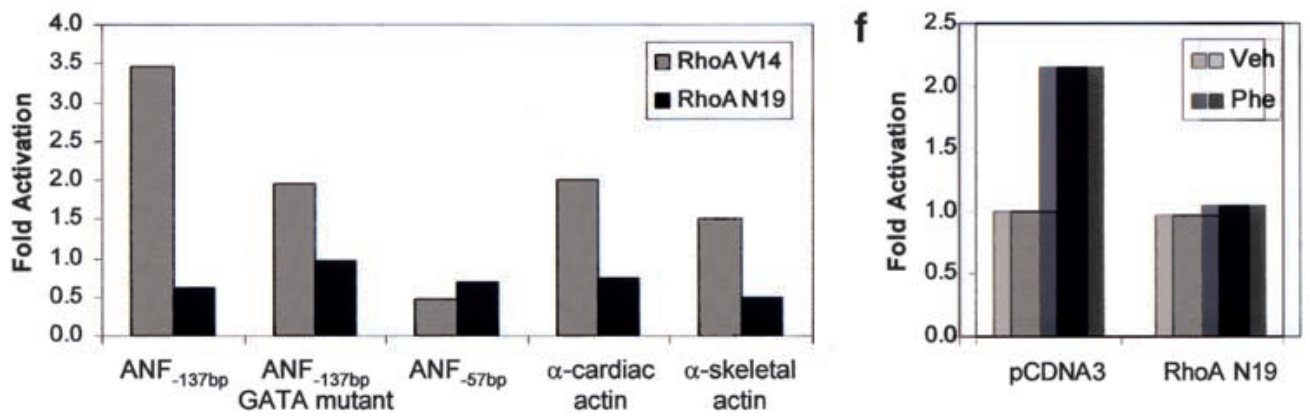

Figure 5. RhoA potentiates GATA-4 transcriptional activity. (a) RhoA V14 does not affect GATA-4 protein level or subcellular localization. Cardiomyocytes transfected with $2 \mu \mathrm{g}$ of pCDNA3 or pCDNA3-myc-RhoA V14 were fixed and costained using an anti-myc antibody (red) and an anti-GATA-4 antibody (green). (b) RhoA potentiates GATA-4 transcriptional activity. NIH 3 T3 cells were transfected with $100 \mathrm{ng}$ of pCDNA3 or pCDNA3-GATA-4 and increasing amounts of pCDNA3-myc-RhoA V14 (0, 50, and 100 $\mathrm{ng}$ ), together with the indicated reporter plasmid. $\mathrm{BNP}_{-50 \mathrm{bp}}$ and $\mathrm{TK}_{-81 \mathrm{bp}}$ are the minimal $\mathrm{BNP}$ and thymidine kinase promoters cloned upstream of a luciferase reporter gene, respectively. (GATA $)_{2}-\mathrm{BNP}_{-50 b p}$ contains two GATA elements from the BNP promoter in front of $\mathrm{BNP}_{-50 \mathrm{bp}}$. Reporter activity was assayed $48 \mathrm{~h}$ after transfection. (c) RhoA-mediated potentiation of GATA-4 transcriptional activation requires RhoA activity. NIH 3 T3 cells were transfected with 100 ng of pCDNA3 or pCDNA3-GATA-4 and increasing amounts of pCDNA3-myc-RhoA V14, pCDNA3-myc-RhoA N19, or pCDNA3-myc-RhoA WT, together with the $\left(\mathrm{GATA}_{2}-\mathrm{BNP}_{-50 b p}\right.$ reporter plasmid. (d) RhoA potentiates GATA-4 activity on cardiac gene promoters. NIH 3T3 cells were transfected with 100 ng of pCDNA3 or pCDNA3-GATA-4 and increasing amounts of pCDNA3-myc-RhoA V14, together with the indicated reporter plasmid. The data shown in $b-d$ are the mean \pm S.D. of 4-6 independent determinations. (e) GATA elements mediate transcriptional regulation by RhoA in cardiomyocytes. ANF, $\alpha$-cardiac actin, and $\alpha$-skeletal actin-luciferase reporter constructs were cotransfected with 300 ng of RhoA expression vectors into primary neonate cardiomyocyte cultures. (f) Functional RhoA proteins are also required for transcriptional activation of the ANF promoter in response to Phe stimulation. The ANF-luciferase reporter (1.5 $\mu \mathrm{g})$ was cotransfected with $1 \mu \mathrm{g}$ of RhoA N19 or the corresponding empty vector (pCDNA3). Phe treatment was as described in Figure 1 . The results in $e$ and $f$ are each from a representative experiment carried out in duplicate. 
Nemer, unpubl.) and have low endogenous RhoA activity (Hill et al. 1995). For these transactivation assays, a GATA-responsive promoter composed of two GATA elements cloned upstream of the BNP -50 bp minimal promoter [(GATA $\left.)_{2}-\mathrm{BNP}_{-50 b p}\right]$ was used (Grépin et al. 1994). Although RhoA V14 had no effect on its own on this promoter, it strongly potentiated GATA-4 transcriptional activity (Fig. 5b). RhoA enhancement of GATA-4 function required RhoA activity, because the inactivated form of RhoA (RhoA N19) or the wild-type form of RhoA (RhoA WT; which is not active in serum-starved conditions) were not able to potentiate GATA-4 activity (Fig. 5c). RhoA V14 potentiation of GATA-4 activity was also observed on cardiac promoters known to be GATA-4 targets (Charron et al. 1999), such as ANF $\left(\mathrm{ANF}_{-137 \mathrm{bp}}\right)$, BNP $\left(\mathrm{BNP}_{-114 \mathrm{bp}}\right), \alpha-\mathrm{MHC}$, and $\alpha$-skeletal actin (Fig. 5d). Mutation of the GATA elements completely abolished the effect of RhoA V14 on GATA-4 transactivation of the ANF and BNP promoters.

To ascertain the in vivo role of GATA factors in mediating the transcriptional effects of RhoA, we cotransfected ANF promoter driven luciferase plasmids with RhoA expression vectors into cardiomyocytes. RhoA V14 enhanced ANF promoter activity by 3.5-fold whereas the dominant-negative form RhoA N19 decreased it by $50 \%$ (Fig. 5e). Moreover, and consistent with previous reports (Sah et al. 1996; Thorburn et al. 1997), RhoA N19 blocked Phe-stimulation of ANF promoter activity (Fig. 5f). This demonstrated that RhoA proteins are required for transcriptional and cytoskeletal response to $\alpha_{1}$-adrenergic stimulation. The findings also indicated the presence of endogenous transcription factors targeted by RhoA in cardiomyocytes. Mutation of the high-affinity GATA element greatly reduced RhoA V14 activation and completely abolished the negative effect of RhoA N19 (Fig. 5e). Neither RhoA V14 nor RhoA N19 had any effect on a minimal, GATA-independent ANF promoter $\left(\mathrm{ANF}_{-57 \mathrm{bp}}\right)$. Under the same conditions, other GATA-dependent cardiac promoters including $\alpha$-MHC, BNP, and skeletal and cardiac $\alpha$-actin were also induced by RhoA V14 or inhibited by RhoA N19 (Fig. 5e; data not shown). Together, these results suggest that in cardiomyocytes, GATA elements mediate transcriptional regulation by RhoA and that GATA dependent pathways are nuclear targets for RhoA.

\section{RhoA stimulates the activity of GATA-4 transcriptional activation domains}

We next sought to determine the mechanism by which RhoA potentiates GATA-4 activity. The effect of RhoA on GATA-4 was not due to increased nuclear GATA-4 protein levels or DNA-binding activity (Fig. 6a,b), suggesting that RhoA modulation of GATA-4 activity may be the result of enhanced transactivation properties. To determine the domain(s) of GATA-4 required for potentiation by RhoA, various GATA-4 deletions and point mutants were tested. Deletion of either the C-terminal (GATA-4 1-332) or N-terminal (GATA-4 200-440) transactivation domain of GATA-4 had no effect on the ca- pacity of RhoA to potentiate GATA-4 activity (Fig. 6c). However, deletion of both activation domains (GATA-4 200-332) completely abolished the effect of RhoA on GATA-4, suggesting that at least one transactivation domain of GATA-4 is required for potentiation by RhoA. As expected, RhoA had no effect on a transcriptionally inactive GATA-4 protein that no longer binds DNA (GATA-4 C273G; Charron et al. 1999).

To determine whether the $\mathrm{N}$ - and $\mathrm{C}$-terminal transactivation domains of GATA-4 are sufficient to support potentiation by RhoA, these domains were fused to the DNA-binding domain of Gal4 (Gal4-DBD) and tested in reporter gene transactivation assays. The $\mathrm{N}$-terminal activation domain of GATA-4 (Gal4-GATA-4 1-207) activated transcription on its own and RhoA V14 (Fig. 6d) further potentiated this response. The C-terminal domain of GATA-4 (Gal4-GATA 329-440) had little autonomous activity in the low serum conditions used; however, in presence of RhoA V14, it activated transcription by 2.7-fold (Fig. 6e). Taken together, these results indicate that RhoA stimulates the transcriptional activity of GATA-4 activation domains.

\section{GATA-4 phosphorylation by p38 MAPK}

RhoA was recently shown to be a potent activator of the p38 mitogen-activated protein kinases (Marinissen et al. 2001), and p38 MAPK activation is sufficient to up-regulate the ANF promoter (Nemoto et al. 1998) and to induce sarcomeric reorganization of cardiomyocytes (Zechner et al. 1997). Moreover, Phe and Et-1 activate the p38 pathway in cardiomyocytes and p38 inhibitors attenuate Phe- and Et-1-dependent myocyte hypertrophy (Zechner et al. 1997; Clerk et al. 1998; Nemoto et al. 1998; Y. Wang et al. 1998). We therefore tested whether RhoA activated p38 MAPK in cardiomyocytes and whether RhoA enhancement of GATA-4 activity occurs through a p38 MAPK pathway. Overexpression of RhoA V14 in cardiomyocytes enhanced the level of activated p38 MAPK as assessed by immunohistochemistry using an anti-phospho-p38 antibody (Fig. 7a). This finding suggests that RhoA activation of $\mathrm{p} 38 \mathrm{MAPK}$ is not restricted to NIH 3T3 cells (Marinissen et al. 2001). Next, we tested the effect of activation of the p38 MAPK pathway on GATA-4 function. p38 or the p38 upstream activator MKK6 markedly induced GATA-dependent transcription in cardiomyocytes (Fig. 7b) and addition of dominant-negative forms of $\mathrm{p} 38$ blocked RhoA potentiation of GATA-4 activity (Fig. 7c). Thus, GATA-4 activity is positively regulated by p38 MAPK.

The GATA-4 protein contains several potential MAP kinase phosphorylation sites within the $\mathrm{N}$ - and C-terminal activation domains. We tested whether p38 MAPK directly phosphorylates GATA-4 activation domains. Using pull-down assays with recombinant p38 proteins, we found that several p38 isoforms interacted directly with GATA-4 through its N-terminal domain (Fig. 7d). Furthermore, p38 $\alpha$ efficiently phosphorylated both $\mathrm{N}$ and C-terminal GATA-4 activation domains in vitro (Fig. 7e). These results suggested that GATA-4 activity 
a

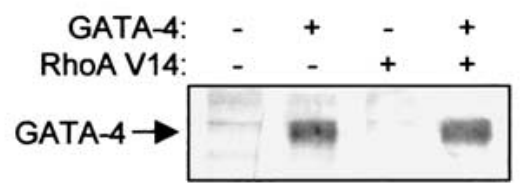

b

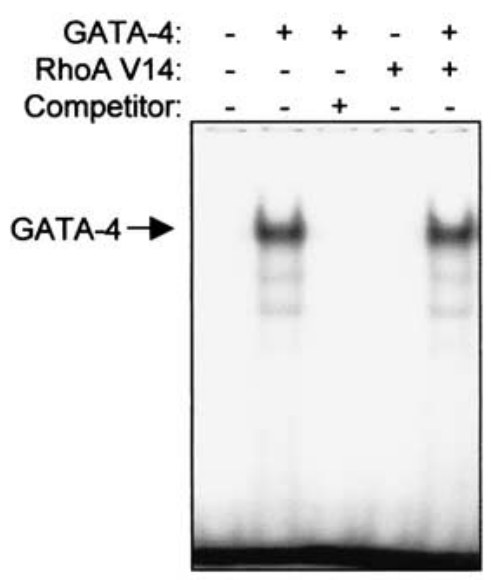

C
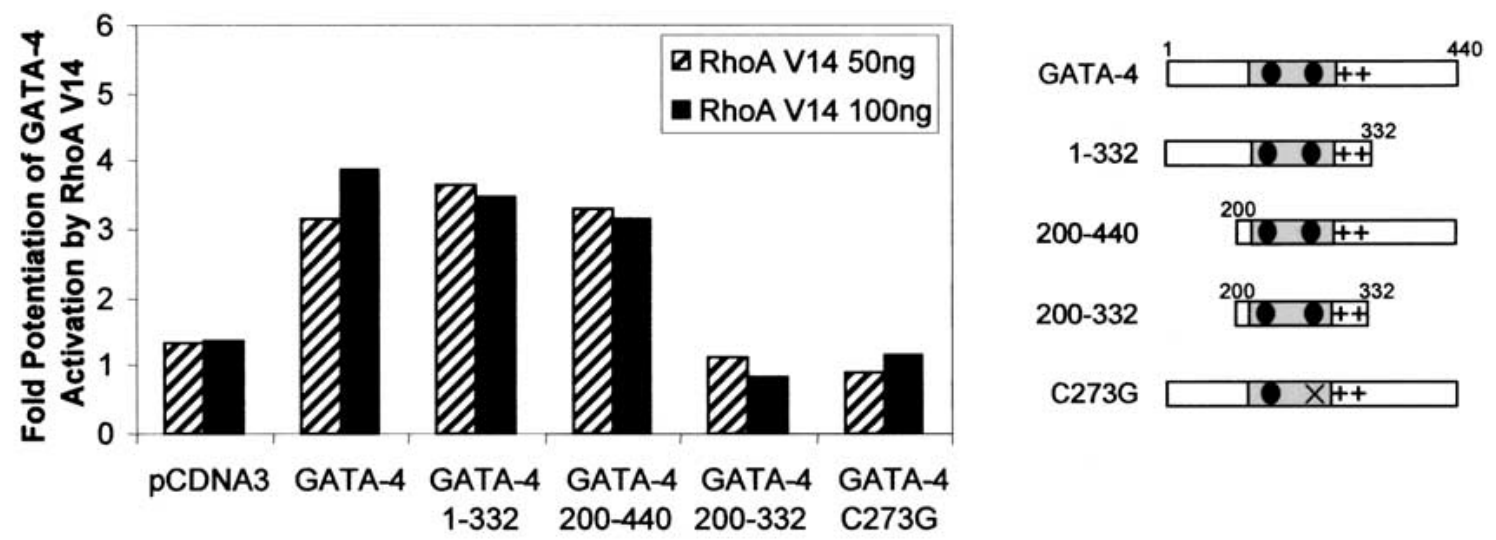

200-332 ${ }^{200} \quad{ }_{10+3}^{332}$

C273G

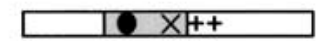

d

e
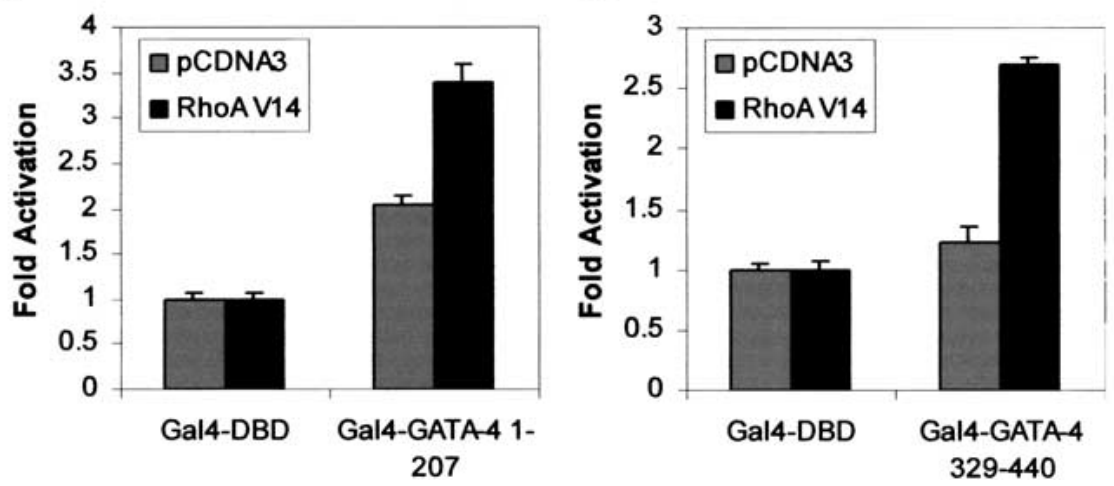

f

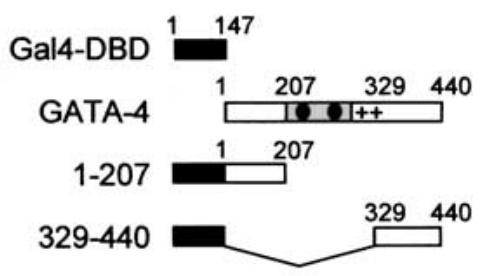

Figure 6. RhoA potentiates GATA-4 activity by stimulating the transcriptional activity of its activation domains. RhoA V14 does not affect $(a)$ GATA-4 protein level or (b) GATA-4 DNA-binding activity, as assessed by Western blot and EMSA, using nuclear extracts of NIH 3T3 cells ectopically expressing either one or both proteins respectively. $(c)$ The $\mathrm{N}$ - or C-terminal transactivation domain of GATA-4 is required for potentiation by RhoA. NIH 3T3 cells were transfected with 100 ng of pCDNA3 or pCDNA3-GATA-4 mutants and increasing amounts of pCDNA3-myc-RhoA V14, together with the $(\mathrm{GATA})_{2}-\mathrm{BNP}_{-50 \mathrm{bp}}$ reporter plasmid. The results are expressed as the ratio of the activity of the GATA-dependent reporter in presence of GATA-4 and RhoA proteins over the activity of the same reporter in presence of GATA-4 proteins alone. The GATA-4 mutants are depicted at right. (d) The N- and (e) C-terminal transactivation domains of GATA-4 are sufficient to support potentiation by RhoA. NIH 3T3 cells were transfected with 100 ng of pCMXGal4-DBD, pCMX-Gal4-GATA-4 1-207, or pCMX-Gal4-GATA-4 329-440 and 100 ng of pCDNA3 or pCDNA3-myc-RhoA V14, together with the $(\mathrm{UAS})_{5}-\mathrm{TK}_{-81 \mathrm{bp}}$ reporter plasmid. The Gal4-GATA-4 constructs are depicted in $f$. The data in $c, d$, and $e$ are the mean \pm S.D. of 2 to 3 experiments each carried out in duplicate.

may be regulated by p38 MAPK phosphorylation. To confirm the in vivo relevance of these observations, we analyzed the phosphorylation status of endogenous GATA-4 in quiescent and in Et-1- and Phe-stimulated 
Charron et al.

a

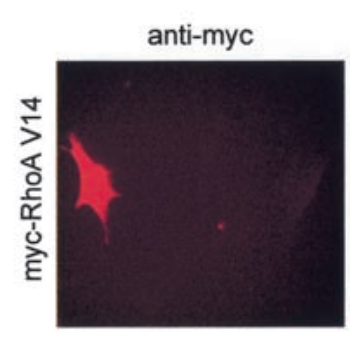

anti-phospho-p38

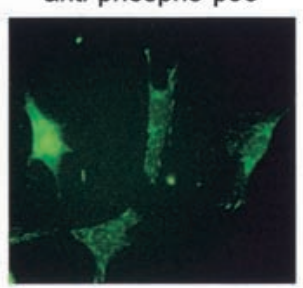

C

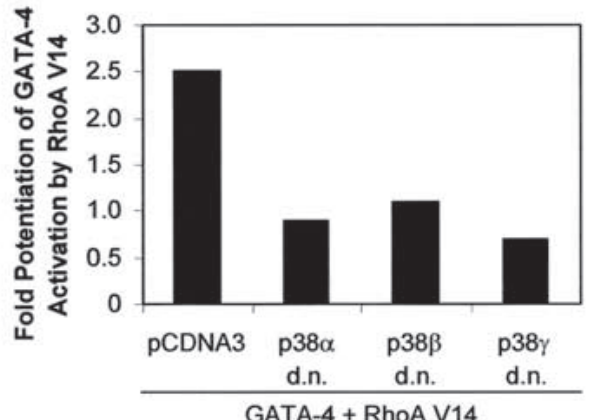

b

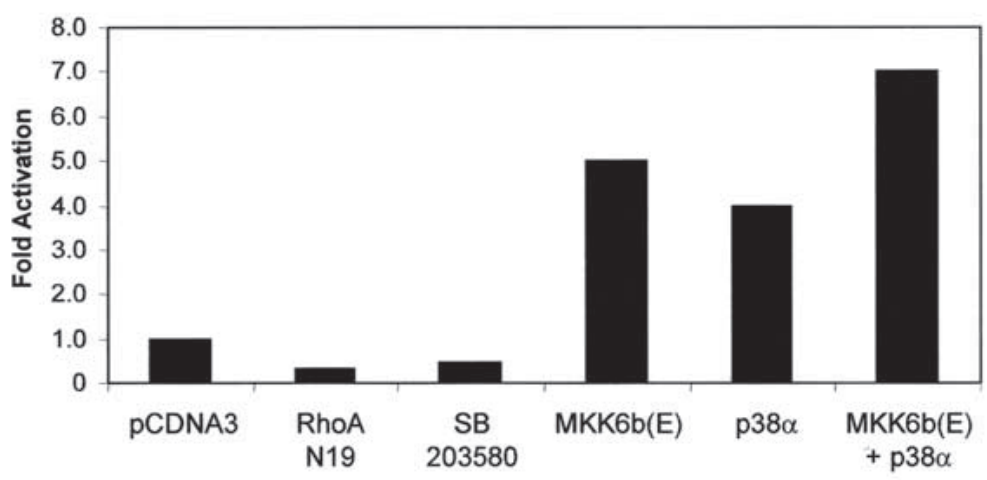

d
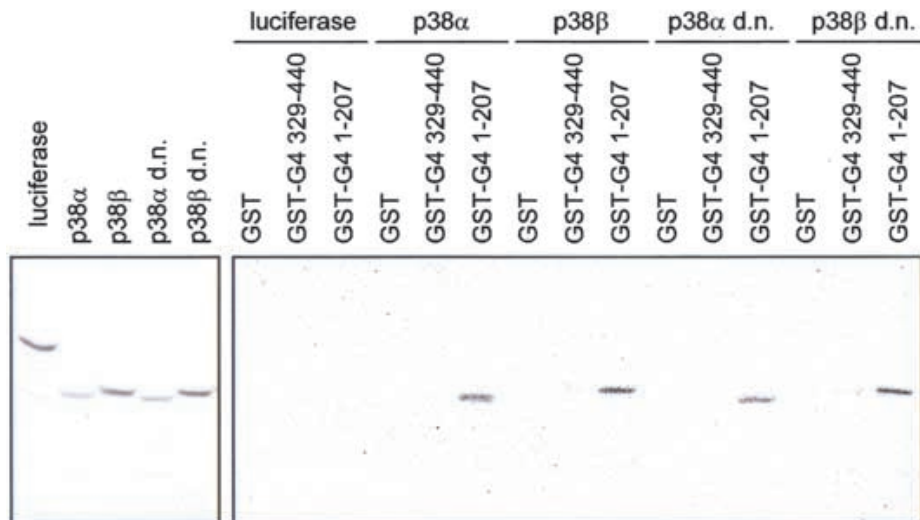

Input e

e

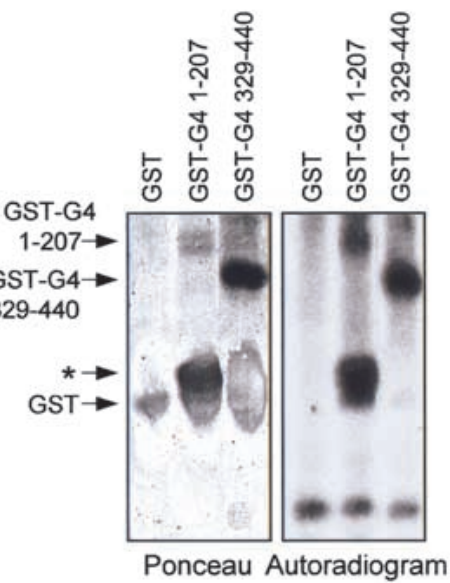

Figure 7. RhoA potentiates GATA-4 transcriptional activity through a p38 MAPK-dependent mechanism. (a) RhoA V14 activates p38 MAPK in cardiomyocytes. Cardiomyocytes were transfected with $1 \mu \mathrm{g}$ of pCDNA3-myc-RhoA V14. Twenty-four hours later, the cells were fixed and costained with anti-myc (red) and anti-phospho-p38 (green) antibodies. Note the induced nuclear and perinuclear phospho-p38 staining in RhoA V14 positive cells. $(b)$ The MKK6/p38 MAPK pathway potentiates endogenous cardiac GATA-4 activity. Cardiomyocytes were transfected with $100 \mathrm{ng}$ of pCDNA3 or activated MKK6 [MKK6b(e)] or p38 $\alpha$ MAPK, together with the (GATA) ${ }_{2}^{-}$ $\mathrm{BNP}_{-50 b p}$ reporter plasmid. (c) Dominant-negative p38 constructs block the potentiation of GATA-4 transcriptional activity by RhoA. NIH 3T3 cells were transfected with 100 ng of pCDNA3 or pCDNA3-GATA-4, 100 ng of pCDNA3-myc-RhoA V14, various dominant-negative (d.n.) isoforms of p38 MAPK, together with the $(\mathrm{GATA})_{2}-\mathrm{BNP}_{-50 \text { pp }}$ reporter plasmid. (d) p38 MAPKs interact with the N-terminal domain of GATA-4. Pull-down assays were performed by incubating GST, GST-GATA-4 1-207, or GST-GATA-4 329-440 with $\left[{ }^{35}\right.$ S $]$ methionine-labeled luciferase or p38 MAPK isoforms. The complexes were washed and resolved by $10 \%$ SDS-PAGE. $(e)$ p38 $\alpha$ phosphorylates GATA-4 in vitro. Activated p38 $\alpha$ adsorbed on agarose beads was incubated with GST, GST-GATA-4 1-207, or GST-GATA-4 329-440 recombinant proteins in the presence of $\left[\gamma^{-32} \mathrm{P}\right]$ ATP. The reaction mixtures were resolved by SDS-PAGE and analyzed by autoradiography. The asterisk denotes a degradation product containing the GATA-4 protein.

cardiomyocytes. As shown in Figure 8a, GATA-4 is a phosphoprotein and its phosphorylation is enhanced by Et-1 and Phe treatment. Phosphorylation occurs mainly on serine residues as determined by phosphoamino acid analysis (Fig. 8b). Phosphopeptide analysis following tryptic digest revealed four major phosphopeptides, one 


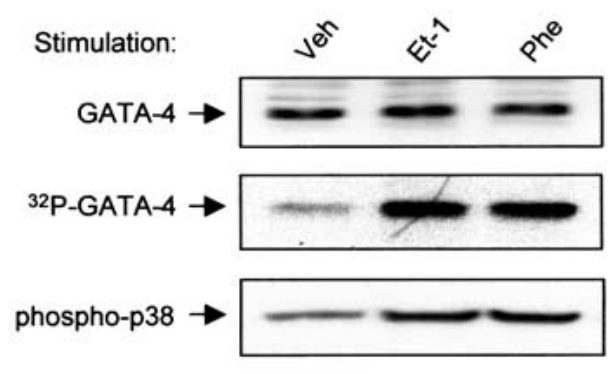

C

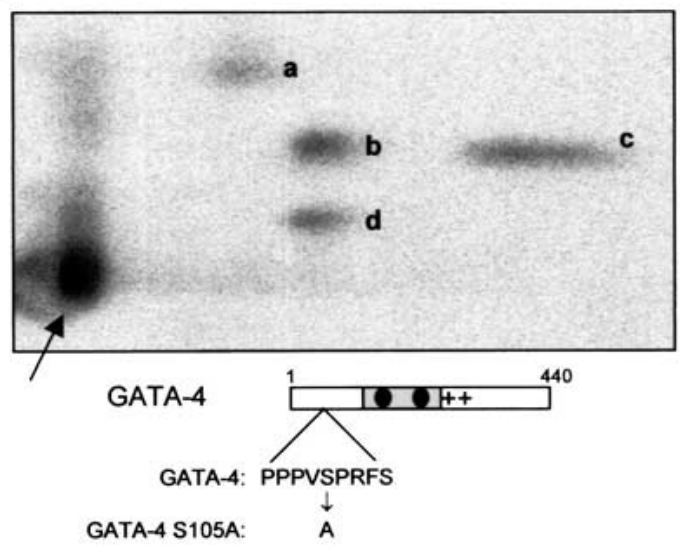

b

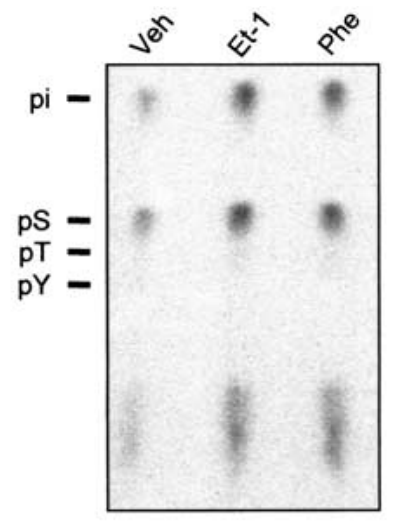

d
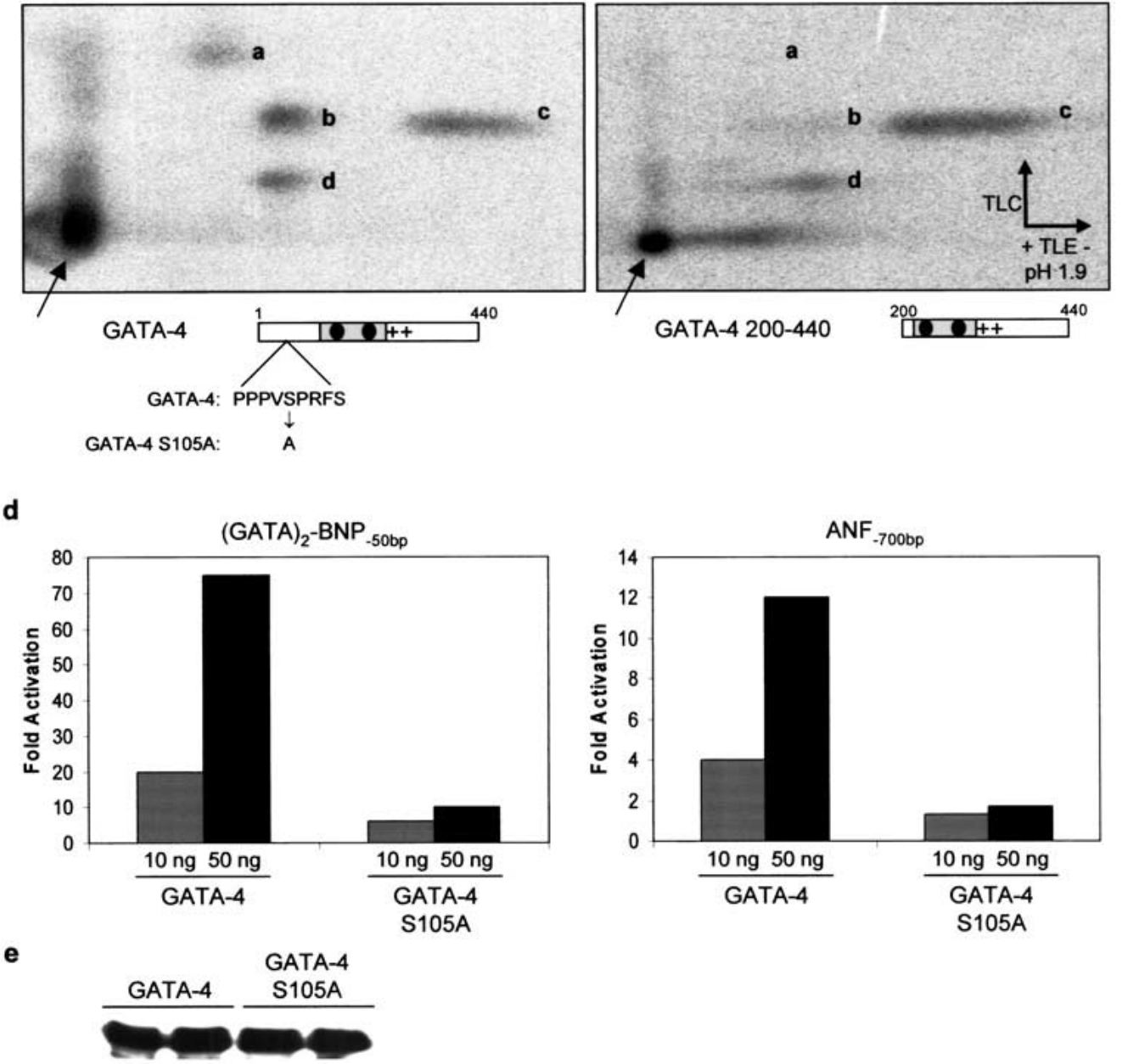

GATA-4 200-440

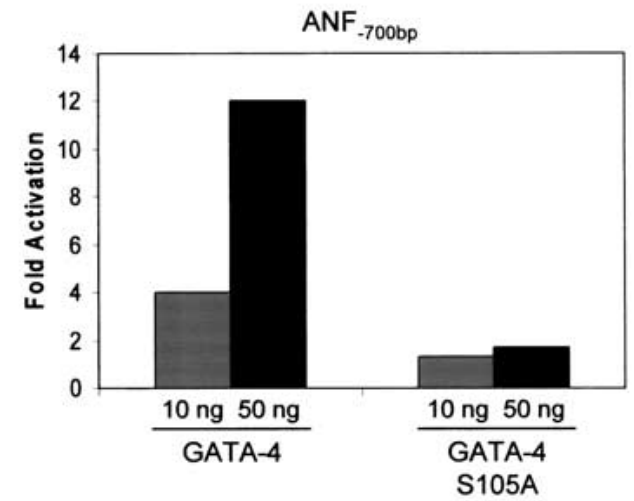

Figure 8. The RhoA-activating agonists Et-1 and Phe induce GATA-4 phosphorylation in cardiomyocytes. (a) Cardiomyocytes were labeled with [ $\left.{ }^{32} \mathrm{P}\right]$ orthophosphate and stimulated for $1 \mathrm{~h}$ with Et-1 or Phe. GATA-4 was immunoprecipitated and the immune complex was resolved by SDS-PAGE ( ${ }^{32} \mathrm{P}-\mathrm{GATA}-4$; middle). In parallel, nuclear extracts were prepared from non-radiolabeled cardiomyocytes and total GATA-4 protein levels were analyzed by Western blot (GATA-4; top). In addition, Western blot analysis of whole-cell extracts using a phospho-specific antibody showed that Et-1 and Phe induce p38 activation in cardiomyocytes (phospho-p38; bottom). (b) Et-1 and Phe induce GATA-4 phosphorylation on serine residues. Radiolabeled GATA-4 bands from $a$ were excised and subjected to phosphoamino acid analysis, as described in Materials and Methods. Note that GATA-4 is phosphorylated almost exclusively on serine residues. (c) Phosphopeptide mapping analysis of ${ }^{32} \mathrm{P}$-labeled wild-type (left) and N-terminal deleted (right) GATA-4; note the absence of spot ' $\mathrm{a}$ ' when the $\mathrm{N}$-terminal domain is removed. (d) A conserved MAPK phosphorylation site is essential for maximal GATA-4 transcriptional activity. Indicated amount of GATA-4 and GATA-4 S105A were transfected with the $\left(\mathrm{GATA}_{2}-\mathrm{BNP}_{-50 \mathrm{bp}}\right.$ or the $\mathrm{ANF}_{-700 \mathrm{bp}}$ reporter plasmids in NIH 3T3 cells and reporter activity was measured $48 \mathrm{~h}$ later. Note the drastic effect of the MAPK consensus site S105A mutation on GATA-4 transcriptional activity, even though both proteins are expressed at equal levels as shown by Western blot analysis (e). 
of which is clearly present within the N-terminal activation domain (Fig. 8c). The highest scoring MAPK phosphorylation site (based on computer-assisted protein kinase substrate search programs) is present in the $\mathrm{N}$-terminal transactivation domain of GATA-4 (S105) and is conserved in all known GATA-4 proteins from Xenopus to human. Mutation of this serine residue to alanine (S105 $\rightarrow$ A) markedly decreased GATA-4 transcriptional activation function without affecting the level of GATA-4 nuclear protein (Fig. 8d,e), indicating that GATA-4 activity may be modulated by MAPK phosphorylation of S105. Mutation of S105 also significantly decreased in vitro phosphorylation of the N-terminal domain of GATA-4 by p38 MAPK (Fig. 9a). To confirm that S105 is a direct target of p38 MAPK, the in vitro phosphorylated GATA-4 1-207 protein was digested with a combination of trypsin and endoprotease GluC, and the resulting labeled peptides were separated by HPLC (Fig. 9b). The major radioactive peak was recovered and subjected to Edman degradation. From the amino acid sequence of GATA-4, this peptide was unambiguously identified as the fragment Gly 96-Arg 107. As shown in Figure 9c, two residues, T100 and S105, within this frag- ment contained radioactivity. These results identify T100 and S105 as two novel p38 MAPK phosphorylation sites within the N-terminal domain of GATA-4. To confirm the in vivo relevance of phosphorylation at S105 in the regulation of GATA-4, a phospho-specific antibody was generated. Using this reagent, GATA-4 was shown to be phosphorylated on S105 in cultured neonatal cardiomyocytes and Et-1 stimulation led to an approximate threefold increase in S105 phosphorylation. These results indicate that GATA-4 is phosphorylated at Ser 105 in response to agonist stimulation of cardiomyocytes. Together, these data suggest that RhoA enhancement of GATA-4 transcriptional activity is likely mediated by a p38 MAPK pathway that phosphorylates GATA-4 transcriptional activation domains.

\section{Discussion}

Rho-like GTPases play a pivotal role in the orchestration of changes in the actin cytoskeleton in response to receptor stimulation and have been implicated in transcriptional activation, cell growth regulation, and oncogenic transformation (Hall 1998). RhoA function in these
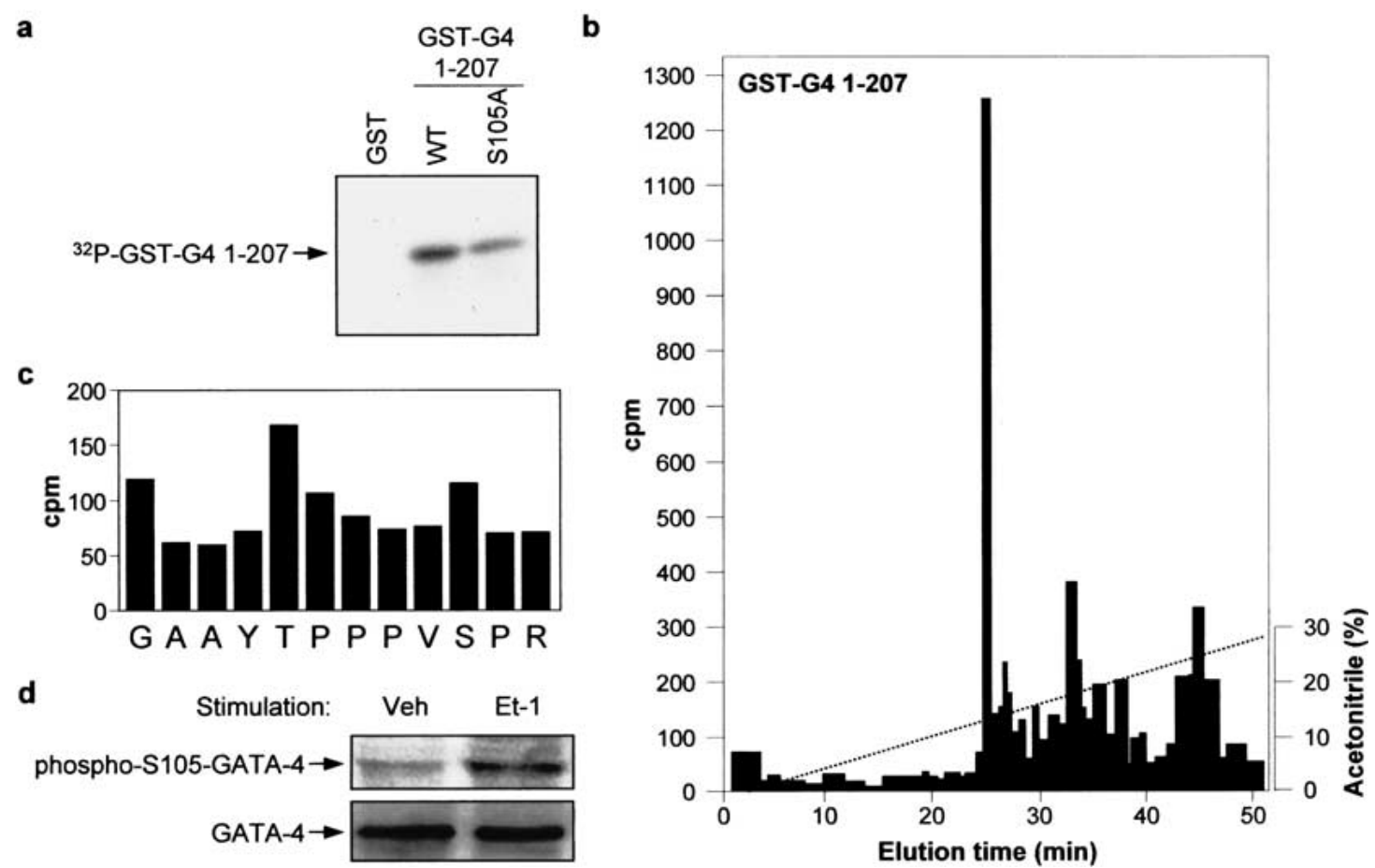

Figure 9. p38 MAPK phosphorylates GATA-4 on Ser 105 in vitro. (a) Recombinant active p38 $\alpha$ was incubated with GST, GSTGATA-4 1-207, or GST-GATA4 1-207 S105A in the presence of $\left[\gamma_{-}{ }^{32} \mathrm{P}\right]$ ATP. The reaction products were analysed by SDS-PAGE and autoradiography. $(b)$ The labeled GST-GATA-4 WT band from $a$ was excised from the gel and digested with trypsin and endoproteinase GluC. The resulting peptides were separated by HPLC on a microbore $\mathrm{C}_{18}$ column developed with a nonlinear acetonitrile gradient. The fractions were collected manually and the radioactivity was measured by Cerenkov counting. $(c)$ The major ${ }^{32} \mathrm{P}$-containing peptide in GST-GATA-4 1-207 was subjected to automatic Edman degradation. The amount of radioactivity released from each degradation cycle was determined by Cerenkov counting. The radioactivity in the first cycle corresponds to noncovalently bound ${ }^{32} \mathrm{P}$ released by the TFA wash during the first cycle. $(d)$ Western blot analysis of lysate proteins from cultured cardiomyocytes treated with vehicle (Veh) or ET-1 for $3 \mathrm{~h}$ using the phospho-S105 GATA-4 or the GATA-4 specific antibodies. Cardiomyocytes were infected with a GATA-4-expressing adenovirus to increase the signal intensity, as described in Liang et al. (2001). Note that Et-1 treatment increases the level of S105 phophorylated GATA-4. 
diverse processes is likely mediated by different effectors (Sahai et al. 1998; Zohar et al. 1998), which remain poorly defined. The data presented in this paper reveal that, in cardiomyocytes, the cardiac-enriched transcription factor GATA-4 is a downstream target of RhoA that regulates a cell-specific pathway of contractile protein gene expression and sarcomere assembly. RhoA and GATA-4 regulate the expression of many genes encoding sarcomeric proteins and both are required for sarcomeric reorganization induced by Et-1 and Phe. RhoA acts on GATA-4 to enhance its transcriptional properties through a p38 MAPK-dependent pathway that phosphorylates GATA-4 on conserved MAPK sites in the Nand C-activation domains. At least, one direct p38 phosphorylation site, S105, is phosphorylated in vivo and its mutation severely impairs GATA-4 activation of target genes, indicating that GATA-4 transactivation domains are modulated by p38 and likely other MAP kinases.

Consistent with its role as an effector of RhoA, a dominant-negative GATA-4 protein blocks RhoA-induced sarcomere formation whereas overexpression of intact GATA-4 is sufficient to induce sarcomeric reorganization of cardiomyocytes. These results identify for the first time a signaling pathway converging on a tissuespecific transcription factor to control sarcomere reorganization and suggest that the cell type-dependent effects of RhoA reflect RhoA modulation of cell-specific transcription factors. At the level of cardiomyocytes, the work presented is consistent with a dual role for RhoA in the cyctoskeletal and transcriptional changes associated with cardiomyocyte hypertrophy. In addition to its direct effect on myofibrillar assembly, RhoA also regulates the expression of sarcomeric proteins and sarcomere reorganization by inducing the transcriptional activity of GATA-4, thereby linking the transcriptional effects of RhoA with its regulatory effects on the cytoskeleton and insuring both rapid and persistent changes in cell shape and function (Fig. 10).

\section{RhoA modulation of transcription}

Several effects of RhoA such as cell growth regulation and transformation imply a role for RhoA in gene expression modulation and RhoA was shown to activate three transcription factors that play important roles in growth factor regulation of gene expression, namely AP-1, NF-кB, and SRF (Hill et al. 1995; Perona et al. 1997; Chang et al. 1998). By far, the most extensively studied RhoA target is the SRE element of c-fos, which is required for RhoA activation of c-fos transcription (Hill et al. 1995). The exact mechanisms by which RhoA induces SRE activity is not defined but has been suggested to involve recruitment of an as-yet-unidentified accessory factor to SRF. More recently, RhoA-mediated SRF activation was shown to require Diaphanous family proteins and Src tyrosine kinase (Tominaga et al. 2000). As depletion of the free cellular actin pool activates SRF (Sotiropoulos et al. 1999), the Diaphanous family proteins may mediate their effect on SRF through their actin polymerization-inducing activity (Watanabe et al. 1999). Nevertheless, the role of the cytoskeleton in RhoA activation of SRE remain unclear given that RhoA effector loop mutants dissociated cytoskeletal changes from SRE activation (Sahai et al. 1998; Zohar et al. 1998).

In addition to its role in cell growth, there is accumulating evidence for a role of RhoA in cell differentiation and organogenesis. Loss-of-function studies in Drosophila and Xenopus revealed that RhoA is required for normal embryonic patterning and eye and neural tube formation (Magie et al. 1999; Wunnenberg-Stapleton et al. 1999). Interference with Rho function also inhibits skeletal myogenesis in vitro and down-regulates expres-

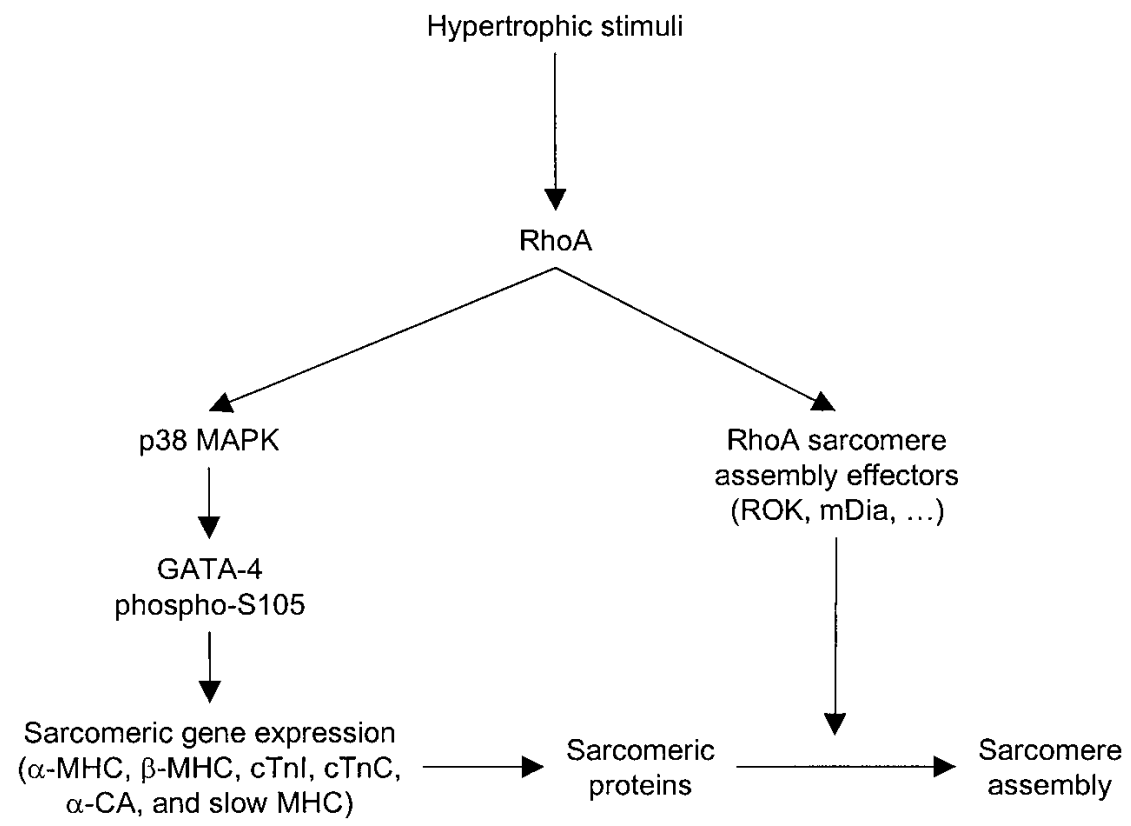

Figure 10. Hypothetical model for the role of GATA-4 as an effector of RhoA and a regulator of cardiomyocyte sarcomere reorganization. Hypertrophic stimuli induce RhoA activity, which in turn potentiates GATA-4 transcriptional activity via p38 MAPK, leading to genetic reprogramming and induction of sarcomeric gene expression. p38 MAPK regulation of GATA-4 involves direct GATA-4 phosphorylation and possibly activation of GATA-4 cofactors like Mef2. RhoA, through activation of effectors such as mDia and $\mathrm{ROK}$, induces polymerization of existing and newly synthesized sarcomeric proteins into contractile filaments, leading to sarcomere formation. Together, these two RhoAdependent pathways would insure initiation and maintenance of the sarcomere reorganization and the hypertrophic state. 
sion of several myogenic factors including Mef2, MyoD, and myogenin (Takano et al. 1998). More recently, it was shown that in addition to up-regulating Mef2 mRNA levels, RhoA could also activate the Mef2 protein in fibroblast cells through a p38 $\gamma$ cascade (Marinissen et al. 2001). Whether RhoA regulation of Mef2 activity can account for RhoA regulation of skeletal muscle differentiation remains to be established.

In the case of GATA-4, RhoA stimulates the transcriptional activity of GATA-4 through potentiation of its transcription activation domains. This may occur through RhoA-mediated induction of GATA-4 phosphorylation and/or regulation of GATA-4 interaction with co-factors such as SRF or Mef2 (Morin et al. 2000, 2001). At present, we cannot exclude the possibility that RhoA regulates GATA interaction with these two factors that are themselves RhoA targets. However, because we had previously shown that both SRF and Mef2 interact with the second zinc finger of GATA-4, RhoA regulation of GATA-4 N- and C-terminal activation domains is most likely independent of SRF and Mef2. The finding that RhoA activation of GATA-4 is p38 MAPK-dependent and that p38 phosphorylates both GATA-4 activation domains is consistent with direct modulation of GATA activity by RhoA. In this respect, it is noteworthy that the p38 pathway has been implicated in the regulation of cardiomyocyte hypertrophy and gene expression in response to Phe and Et-1 (Zechner et al. 1997; Clerk et al. 1998; Nemoto et al. 1998; Y. Wang et al. 1998). Given that Et-1 and Phe augment both p38 (Nemoto et al. 1998; this study) and RhoA (this study) activities in cardiomyocytes, that activated RhoA enhances phospho-p38 levels, and that GATA-4 is necessary for Et-1 and Phe as well as RhoA induced sarcomere reorganization, it is tempting to suggest the existence of a linear RhoA-p38GATA-4 cascade linking the Et-1 and $\alpha_{1}$-adrenergic G protein-coupled receptors to cytoskeletal and nuclear changes. Such a pathway would be required for the induction and/or maintenance of the hypertrophic phenotype. The p38 MAPK pathway was also shown to be important for in vitro cardiomyocyte differentiation (Davidson and Morange 2000). Given the role of GATA-4 as a survival factor for cardiomyocytes (Grépin et al. 1997), it is tempting to suggest that p38 may directly regulate GATA-4 activity during various stages of myocyte differentiation. In addition to p38, activation of the ERK and JNK kinases has been linked to regulation of various myocyte functions including growth and survival (Y. Wang et al. 1998; Andreka et al. 2001; Molkentin and Dorn 2001). Interestingly, S105 is robustly phosphorylated in vitro by ERK1/2 and infection of cardiomyocytes with adenovirus vectors expressing activated MEK1, MKK7, or MKK6 induces phospho S105 GATA-4 to varying degrees without altering total GATA-4 levels (Q. Liang and J.D. Molkentin, unpubl.). Thus, GATA-4, and more specifically phosphorylation of ser 105, may represent a converging nuclear target for various MAPK cascades. Whether this involves Rho or other members of the small GTPase family that were shown to act upstream of different MAPKs (Minden et al. 1995; Renshaw et al. 1996; Marinissen et al. 1999; Clerk et al. 2001) will be worth testing because the kinases linking Rho to GATA proteins may vary depending on the cell environment as already suggested in yeast (Evangelista et al. 1997; Chandarlapaty and Errede 1998).

\section{Evolutionary conservation of the Rho/GATA signaling pathway}

In addition to its role in adaptive cardiomyocyte response, the Rho-GATA pathway may be important for embryonic heart and possibly other tissue development. Both Rho GTPase and GATA factors are involved in cell motility during development. For example, the GATAc/ grain GATA transcription factor has been shown to regulate cell movement in Drosophila (Brown and CastelliGair 2000) and GATA-4 null mice exhibit cardia bifida because of a migration defect of the heart precursors to the midline (Kuo et al. 1997; Molkentin et al. 1997). Mice harboring a mutation in another gene, fibronectin, that has been linked to the Rho signaling pathway present a phenotype similar to that of the Gata4 null mice (George et al. 1993, 1997). Fibronectin, a component of the extracellular matrix and a ligand for integrin adhesion receptors, is known to signal to the actin cytoskeleton through Rho GTPase proteins to effect cytoskeletal changes necessary for cell motility during development (Schwartz and Shattil 2000). Together with the established role of Rho GTPases in cell motility, these results raise the possibility that defective Rho/GATA-4 signaling (either because of the lack of GATA-4 or the lack of Rho activation by fibronectin) may be the unifying theme that could explain why mutations in such different gene types (a transcription factor and an extracellular matrix component) cause a similar phenotype.

The role of GATA transcription factors in Rho-induced cytoskeletal reorganization likely extends to other muscle and non-muscle cell types. RhoA and two of its effectors, $\mathrm{ROK} \alpha$ and $\mathrm{ROK} \beta$, have been shown to be involved in smooth muscle contraction (Hirata et al. 1992; Gong et al. 1996; Kimura et al. 1996; Kureishi et al. 1997; Uehata et al. 1997). Given that the GATA transcription factor family member GATA-6 is expressed in smooth muscle cells (Suzuki et al. 1996) and that our results indicate that RhoA also modulates GATA-6 transcriptional activity (data not shown), it is tempting to speculate that a RhoA/GATA-6 pathway might regulate smooth muscle contraction. In addition, it is well established that Rho family GTPases act as unique molecular switches at several critical checkpoints in lymphocyte development and function and more particularly in the organization, via the actin cytoskeleton, of a specialized zone required for sustained signaling between $\mathrm{T}$ cells and antigen presenting cells (Acuto and Cantrell 2000). Given the essential function of GATA-3 in T cell differentiation and activation (Kuo and Leiden 1999), it would be worthwhile to test the role of GATA-3 as a mediator of Rho signaling in these cells.

Finally, during cell-fate determination in yeast, the GATA transcription factor Ashlp is regulated by the 
Cdc42p/Rho signaling pathway effector Bnilp (a Diaphanous family protein) (Evangelista et al. 1997; Takizawa et al. 1997). In addition, Ash1p is also regulated by the Cdc42p effector Ste20p (a Ser/Thr kinase homologous to the mouse Cdc42 effector p65/PAK) during regulation of filamentous pseudohyphal growth in response to nitrogen starvation (Chandarlapaty and Errede 1998). Despite the fact that the molecular mechanism underlying Ash $1 \mathrm{p}$ regulation by Rho proteins remains unknown, it is nonetheless interesting to note that the functional interaction between GATA transcription factors and Rho GTPases is evolutionarily conserved from yeast to mammals.

\section{Materials and methods}

\section{Plasmids and adenoviral vectors}

The recombinant replication-deficient adenoviruses type 5 (Ad5) expressing a nuclear localization signal (nls)-lacZ and antisense directed specifically toward GATA-4 were described previously (French et al. 1994; Charron et al. 1999). The GATA-4 overexpressing adenovirus was a kind gift from A. Aplin and C.E. Murry (University of Washington) and was generated by subcloning the $X b a I$ fragment from the rat GATA-4 cDNA (Grépin et al. 1994) into the Ad1-RSV shuttle vector. Putative adenovirus clones were plaque-purified, screened for inserts, propagated, isolated, and titered according to the protocol of Graham and Prevec (1991), to produce viral stocks with titers $>2 \times 10^{9} \mathrm{PFU} / \mathrm{mL}$.

ANF and BNP reporter plasmids and the various GATA-4, GATA-5, and GATA-6 constructs have been described previously (Argentin et al. 1994; Grépin et al. 1994; Durocher et al. 1996; Charron et al. 1999; Nemer et al. 1999; Morin et al. 2000). The Gal4-DNA-binding domain (DBD)-GATA-4 fusions were generated by subcloning the PCR-amplified N-terminal (codons 1-207) and C-terminal (codons 329-440) fragments of the rat GATA-4 cDNA into pCMX-Gal4-DBD. All constructs were confirmed by sequencing. pCDNA3-myc-RhoA wild type, pCDNA3-myc-RhoA V14, and pCDNA3-myc-RhoA N19 expression vectors were kind gifts from Dr. Nathalie Lamarche (McGill University, Montréal, Canada). Expression vectors encoding wild-type as well as catalytically inactive mutants of p38 isoforms [P38(AF)] were kindly provided by Dr. J. Han (The Scripps Research Institute) and were described previously (Ludwig et al. 1998).

\section{Cell culture, infections, and transfections}

Neonatal cardiomyocytes were prepared from 4-day-old Sprague-Dawley rats as described previously (Charron et al. 1999). The following day, the medium was changed for serum-free hormonally defined medium (SFHF) (Argentin et al. 1994). Four hours later, cardiomyocytes were either infected or transfected. Infections were performed at a multiplicity of infection (MOI) of 4 (unless indicated otherwise) by adding the appropriate recombinant adenovirus to the culture media overnight. Transfections were done using calcium phosphate precipitation with $1.5 \mu \mathrm{g}$ of luciferase reporter plasmid and various amounts of RhoA and GATA expression vectors (see Figures 5-7, legends) per $9.5 \mathrm{~cm}^{2}$ culture dish. The amount of DNA was kept constant using the empty expression vector. Sixteen to twenty hours later, cardiomyocytes were washed twice with Dulbecco's modified Eagle's medium (DMEM, Canadian Life Technologies) and SFHF me- dium was added. Cardiomyocytes were fixed or harvested 48-72 $\mathrm{h}$ after infection or transfection. When required, SFHF was supplemented with vehicle, Et-1 (100 nM), or Phe $(100 \mu \mathrm{M})$ for a period of $48 \mathrm{~h}$ before fixation or harvesting. Luciferase activity was assayed using a Berthold LB 953 luminometer. The results shown are the mean \pm SD of at least two independent experiments carried out in duplicate.

NIH 3T3 cells were plated at a density of 100,000 cells per 9.5 $\mathrm{cm}^{2}$ in 6-well plates (Falcon) in DMEM supplemented with $10 \%$ FBS (Qualified grade, Canadian Life Technologies). Transfections were carried out as in cardiomyocytes, except that after the DMEM washes, DMEM supplemented with 0.5\% FBS was added and cells were harvested $48 \mathrm{~h}$ after transfection.

\section{RNA extraction and Northern blots}

Total RNA was isolated from cardiomyocytes by the guanidium thiocyanate-phenol-chloroform method and blotted as described previously (Charron et al. 1999). Blots were hybridized with random prime-labeled cDNA probes for BNP, $\alpha-S A, \alpha-C A$, and GAPDH, exposed to a PhosphorImager screen, and analyzed with ImageQuant (Molecular Dynamics).

\section{Nuclear extracts and electrophoretic mobility shift assays (EMSAs)}

Nuclear extracts were prepared as described previously (Morin et al. 2000). Binding reactions were performed in $20-\mu \mathrm{L}$ reaction mixtures with $3 \mu \mathrm{g}$ of nuclear extracts in a buffer containing 12 mM HEPES (pH 7.9), $5 \mathrm{mM} \mathrm{MgCl}_{2}, 60 \mathrm{mM} \mathrm{KCl}, 4 \mathrm{mM}$ Tris- $\mathrm{HCl}$ (pH 7.9), $0.6 \mathrm{mM}$ EDTA, $0.6 \mathrm{mM}$ DTT, $0.5 \mathrm{mg} / \mathrm{mL}$ BSA, $1 \mu \mathrm{g}$ of poly[d(I-C)], $12 \%$ glycerol, and $20,000 \mathrm{cpm}$ of radiolabeled double-stranded -120 bp ANF GATA probe (Charron et al. 1999) for $20 \mathrm{~min}$ at room temperature. Reactions were loaded on a $4 \%$ polyacrylamide gel and run at $200 \mathrm{~V}$ at room temperature in $0.25 \times$ TBE. The gel was dried and exposed to a PhosphorImager screen (Molecular Dynamics).

\section{Western blots}

Protein extracts were boiled in Laemmli buffer and resolved by SDS-PAGE. Proteins were transferred on Hybond-PVDF membrane, immunoblotted, and revealed using ECL Plus (Amersham Pharmacia Biotechnology) as described by the manufacturer. Goat GATA-4 supershift antibody (Santa Cruz Biotechnology) was used at a dilution of $1 / 1000$ and was revealed with an anti-goat horseradish peroxydase antibody (Sigma) at a dilution of $1 / 100,000$.

\section{Immunofluorescence}

Cardiomyocytes were washed twice with PBS, fixed with 3\% paraformaldehyde in PBS for $15 \mathrm{~min}$ at room temperature, permeabilized with $0.3 \%$ Triton X-100 and $3 \%$ paraformaldehyde in PBS for $1 \mathrm{~min}$ at room temperature, and washed three times with PBS. Cardiomyocytes were then processed for immunofluorescence as described (Viger et al. 1998). The GATA-4 antibody was used at a dilution of $1 / 500$ and was revealed with a biotinylated anti-goat antibody (1/200; Vector Laboratories) followed by avidin-rhodamine or avidin-FITC antibody $(1 / 200$; Vector Laboratories). The anti-myc monoclonal antibody (Santa Cruz Biotechnology) was used at a dilution of $1 / 1000$ and was revealed with an anti-mouse-FITC or anti-mouse-rhodamine antibody (1/200; Vector Laboratories). Phalloidin-FITC (Sigma) was used at $1 \mu \mathrm{g} / \mathrm{mL}$. To score for reorganized cells, random fields (minimum of 10 per dish) were taken and the number of 
cardiomyocytes harboring striated acto-myosin fibers extending from one extremity of the cell to the other was counted and divided by the total number of cardiomyocytes in the same field. These observations were performed blindly.

\section{Rho activity assays}

Whole-cell extracts were prepared from cardiomyocytes and the active form of Rho (Rho-GTP) was selectively affinity-precipitated from these extracts using a GST-Rhotekin fragment coupled to glutathione-Sepharose, according to the manufacturer protocol (Upstate Biotechnology). The affinity-precipitated complexes were resolved by SDS-PAGE, transferred to PVDF, and revealed using an anti-Rho antibody.

\section{Kinase pull-down assays}

The recombinant GST-GATA-4 1-207 and GST-GATA-4 329440 proteins were produced according to the manufacturer's protocol (Pharmacia Biotech). $\left[{ }^{35} \mathrm{~S}\right]$ methionine-labeled luciferase, $\mathrm{p} 38 \alpha, \mathrm{p} 38 \beta, \mathrm{p} 38 \alpha$ dominant-negative, and $\mathrm{p} 38 \beta$ dominantnegative MAPK proteins were produced by in vitro transcription and translation using the TNT system (Promega). Pull-down assays were performed by incubating $2 \mu \mathrm{g}$ of GST-GATA- 4 proteins with $5 \mu \mathrm{L}$ of glutathione-Sepharose in binding buffer $(50$ $\mathrm{mM}$ Tris at $\mathrm{pH} 7.7,150 \mathrm{mM} \mathrm{NaCl}, 0.3 \% \mathrm{NP}-40,0.5 \mathrm{mM}$ PMSF, $0.25 \% \mathrm{BSA}$ ) for $30 \mathrm{~min}$ at $4^{\circ} \mathrm{C}$. Then, $1 \mu \mathrm{L}$ of labeled luciferase or p38 MAPK was added to the binding reactions and further incubated for $2 \mathrm{~h}$. The complexes were washed 3 times with binding buffer, once with binding buffer without BSA, resolved by SDS gel electrophoresis, and exposed to a PhosphorImager screen.

\section{In vitro phosphorylation of GATA-4}

To isolate the activated form of $\mathrm{p} 38 \alpha$, quiescent Rat 1 cells were subjected to a heat-shock treatment at $42^{\circ} \mathrm{C}$ for $15 \mathrm{~min}$. Cell lysates were then prepared and incubated for $4 \mathrm{~h}$ at $4^{\circ} \mathrm{C}$ with the p38 $\alpha$-specific antibody HSK592 as described (Meloche et al. 2000). The immune complexes were washed three times with lysis buffer, and twice with kinase assay buffer $(10 \mathrm{mM}$ Hepes at $\mathrm{pH} 7.4,10 \mathrm{mM} \mathrm{MgCl}_{2}, 1 \mathrm{mM}$ DTT, $10 \mathrm{mM} \beta$-glycerophosphate). The beads were then resuspended in a total volume of 40 $\mu \mathrm{L}$ of kinase assay buffer containing $5 \mu \mathrm{g}$ of GST-GATA-4, 50 $\mu \mathrm{M}$ ATP , and $5 \mu \mathrm{Ci}\left[\gamma_{-}{ }^{32} \mathrm{P}\right] \mathrm{ATP}$. The reaction was initiated with ATP, incubated at $30^{\circ} \mathrm{C}$ for $60 \mathrm{~min}$ and stopped by addition of $2 \times$ Laemmli's sample buffer. The proteins were resolved by SDSPAGE and transferred to a PVDF membrane. The membrane was stained with Ponceau-S and analyzed by autoradiography.

\section{HPLC and peptide sequencing}

For sequencing analysis, purified GST-GATA-4 1-207 proteins $(10 \mu \mathrm{g})$ were phosphorylated by $50 \mathrm{ng}$ of recombinant active p38 (Upstate Biotechnology) in $40 \mu \mathrm{L}$ of kinase buffer containing $5 \mu \mathrm{Ci}\left[\gamma_{-}{ }^{32} \mathrm{P}\right] \mathrm{ATP}$ for $60 \mathrm{~min}$ at $30^{\circ} \mathrm{C}$, according to the manufacturer's instructions. After SDS-PAGE and staining, the protein bands were excised from the gel and subjected to DTT reduction and iodoacetamide alkylation prior to enzymatic digestion (Hellman et al. 1995; Williams et al. 1997). The proteins were first digested with sequencing grade trypsin (Promega) overnight at $37^{\circ} \mathrm{C}$, followed by addition of sequencing grade endoproteinase GluC (Promega) for another $4 \mathrm{~h}$. The peptides were extracted with $1 \%$ TFA $/ 60 \%$ acetonitrile at $60^{\circ} \mathrm{C}$ and separated by HPLC on a Vydac microbore $\mathrm{C}_{18}$ column using an Applied Biosystems 130A Separation System. The column was developed at a flow rate of $150 \mu \mathrm{L} / \mathrm{min}$ using the following gradient program: $3 \mathrm{~min}$ in solvent $\mathrm{A}(0.1 \%$ trifluoroacetic acid [TFA] in water), $0 \%-50 \%$ solvent $\mathrm{B}(0.08 \%$ TFA in $70 \%$ acetonitrile) during the next $60 \mathrm{~min}$, and $50 \%-100 \%$ solvent $\mathrm{B}$ in the remaining $7 \mathrm{~min}$. The fractions were detected by absorbance at $220 \mathrm{~nm}$, manually collected, and counted by Cerenkov to identify the radioactive phosphopeptides. The major labeled peptide was coupled to a Prosorb disc (Applied Biosystems) and subjected to automatic Edman degradation on a model 494 cLC procise Sequencer using the general protocol of Hewick et al. (1981). Fractions were collected after each degradation cycle and the radioactivity measured by Cerenkov counting.

\section{Analysis of endogenous GATA-4 phosphorylation} and phosphoamino acid analyses

Neonatal cardiomyocytes were plated at $4 \times 10^{6}$ cells per 100 $\mathrm{mm}$ dish. Three days after plating, cardiomyocytes were metabolically labeled by washing and replacing the SFHF medium with $4 \mathrm{~mL}$ of phosphate-free DME supplemented with $2 \mathrm{mCi}$ $\left[{ }^{32} \mathrm{P}\right]$ phosphoric acid for $3 \mathrm{~h}$. Cardiomyocytes were subsequently stimulated by adding Et-1 (100 nM) or Phe $(100 \mu \mathrm{M})$ for $1 \mathrm{~h}$. Cells were washed and harvested in RIPA buffer, and radiolabeled GATA- 4 was immunoprecipitated using $5 \mu \mathrm{L}$ of antiGATA-4 antibody (Santa Cruz), at $4^{\circ} \mathrm{C}$. After $2 \mathrm{~h}, 20 \mu \mathrm{L}$ of protein-A/G agarose (Santa Cruz) was added and the immunocomplexes were further incubated for $2 \mathrm{~h}$ at $4^{\circ} \mathrm{C}$. Following four washes in RIPA buffer, the immunocomplexes were resuspended in Laemmli's sample buffer, boiled $5 \mathrm{~min}$, resolved by SDS-PAGE, and transferred to a PVDF membrane. The membrane was analyzed by autoradiography. For phosphoamino acid and phosphopeptide analyses following trypsin digestion, the radiolabeled GATA-4 bands were excised from the PVDF membrane and processed as described (Gopalbhai and Meloche 1998).

\section{Anti-phospho-GATA-4 (105) antibody and Western blotting}

Phospho-specific rabbit antiserum was generated using the following peptide sequence in GATA-4; YTPPPV-phospho-serinePRFSFP (amino acids 99-111) by Research Genetics (Huntsville, AL). Collected antiserum was cross-absorbed with an identical peptide, but without the phosphorylation group at Ser 105, then affinity purified. The resulting antiserum was used at a 1:600 dilution in $5 \%$ milk in TBST overnight at $4{ }^{\circ} \mathrm{C}$. Secondary antibody was applied at a dilution of $1: 1000$ in $5 \%$ milk in TBST for $1 \mathrm{~h}$ at room temperature for quantitative chemiluminescent detection using the Vistra enhanced chemiflorescence protocol (Amersham). Images were scanned utilizing a Storm 860 (Molecular Dynamics).

\section{Acknowledgments}

We are grateful to Drs. Charles E. Murry and Alfred Aplin for sharing their GATA-4 adenovirus and to Dr. Pierre Paradis for the generation of the original GATA-4 adenovirus that was used to initiate these studies. We thank Dr. Nathalie Lamarche for reagents and critical reading of the manuscript, Ms. France Dumas of the National Research Council for help with peptide sequencing, and members of the Nemer laboratory for helpful discussions. We acknowledge the technical help of Chantal Lefebvre and the secretarial assistance of Lise Laroche. This work was supported by grants from the Canadian Institutes for Health Research (CIHR) and from the Société de recherches sur le cancer. F.C. and M.A. are recipients of research studentships from the National Cancer Institute of Canada and the CIHR, 
respectively. S.M. is a CIHR scientist and M.N. holds a Canada Chair in Molecular Biology.

The publication costs of this article were defrayed in part by payment of page charges. This article must therefore be hereby marked "advertisement" in accordance with 18 USC section 1734 solely to indicate this fact.

\section{References}

Acuto, O. and Cantrell, D. 2000. T cell activation and the cytoskeleton. Annu. Rev. Immunol. 18: 165-184.

Andreka, P., Zang, J., Dougherty, C., Slepak, T.I., Webster, K.A., and Bishopric, N.H. 2001. Cytoprotection by Jun kinase during nitric oxide-induced cardiac myocyte apoptosis. Circ. Res. 88: 305-312.

Aoki, H., Izumo, S., and Sadoshima, J. 1998. Angiotensin II activates RhoA in cardiac myocytes: A critical role of RhoA in angiotensin II-induced premyofibril formation. Circ. Res. 82: 666-676.

Argentin, S., Ardati, A., Tremblay, S., Lihrmann, I., Robitaille, L., Drouin, J., and Nemer, M. 1994. Developmental stagespecific regulation of atrial natriuretic factor gene transcription in cardiac cells. Mol. Cell. Biol. 14: 777-790.

Bar-Sagi, D. and Hall, A. 2000. Ras and Rho GTPases: A family reunion. Cell 103: 227-238.

Brown, S. and Castelli-Gair, H. 2000. Drosophila grain encodes a GATA transcription factor required for cell rearrangement during morphogenesis. Development 127: 4867-4876.

Chandarlapaty, S. and Errede, B. 1998. Ash1, a daughter cellspecific protein, is required for pseudohyphal growth of Saccharomyces cerevisiae. Mol. Cell. Biol. 18: 2884-2891.

Chang, J.H., Pratt, J.C., Sawasdikosol, S., Kapeller, R., and Burakoff, S.J. 1998. The small GTP-binding protein Rho potentiates AP-1 transcription in T cells. Mol. Cell. Biol. 18: 49864993.

Charron, F. and Nemer, M. 1999. GATA transcription factors and cardiac development. Sem. Cell Dev. Biol. 10: 85-91.

Charron, F., Paradis, P., Bronchain, O., Nemer, G., and Nemer, M. 1999. Cooperative interaction between GATA-4 and GATA-6 regulates myocardial gene expression. Mol. Cell. Biol. 19: 4355-4365.

Clerk, A. and Sugden, P.H. 2000. Small guanine nucleotidebinding proteins and myocardial hypertrophy. Circ. Res. 86: 1019-1023.

Clerk, A., Michael, A., and Sugden, P.H. 1998. Stimulation of the p38 mitogen-activated protein kinase pathway in neonatal rat ventricular myocytes by the $\mathrm{G}$ protein-coupled receptor agonists, endothelin-1 and phenylephrine: A role in cardiac myocyte hypertrophy? J. Cell Biol. 142: 523-535.

Clerk, A., Pham, F.H., Fuller, S.J., Sahai, E., Aktories, K., Marais, R., Marshall, C., and Sugden, P.H. 2001. Regulation of mitogen-activated protein kinases in cardiac myocytes through the small G protein Rac1. Mol. Cell. Biol. 21: 1173-1184.

Davidson, S.M. and Morange, M. 2000. Hsp25 and the p38 MAPK pathway are involved in differentiation of cardiomyocytes. Dev. Biol. 218: 146-160.

Durocher, D., Chen, C.Y., Ardati, A., Schwartz, R.J., and Nemer, M. 1996. The ANF promoter is a downstream target for Nkx-2.5 in the myocardium. Mol. Cell. Biol. 16: 46484655.

Durocher, D., Charron, F., Warren, R., Schwartz, R.J., and Nemer, M. 1997. The cardiac transcription factors Nkx2-5 and GATA-4 are mutual cofactors. EMBO J. 16: 5687-5696.

Evangelista, M., Blundell, K., Longtine, M.S., Chow, C.J., Ad, Pringle, J.R., Peter, M., and Boone, C. 1997. Bnilp, a yeast formin linking cdc $42 \mathrm{p}$ and the actin cytoskeleton during polarized morphogenesis. Science 276: 118-122.

French, B.A., Mazur, W., Ali, N.M., Geske, R.S., Finnigan, J.P., Rodgers, G.P., Roberts, R., and Raizner, A.E. 1994. Percutaneous transluminal in vivo gene transfer by recombinant adenovirus in normal porcine coronary arteries, atherosclerotic arteries, and two models of coronary restenosis. Circulation 90: 2402-2413.

George, E.L., Georges-Labouesse, E.N., Patel-King, R.S., Rayburn, H., and Hynes, R.O. 1993. Defects in mesoderm, neural tube and vascular development in mouse embryos lacking fibronectin. Development 119: 1079-1091.

George, E.L., Baldwin, H.S., and Hynes, R.O. 1997. Fibronectins are essential for heart and blood vessel morphogenesis but are dispensable for initial specification of precursor cells. Blood 90: 3073-3081.

Gong, M.C., Iizuka, K., Nixon, G., Browne, J.P., Hall, A., Eccleston, J.F., Sugai, M., Kobayashi, S., Somlyo, A.V., and Somlyo, A.P. 1996. Role of guanine nucleotide-binding proteins-rasfamily or trimeric proteins or both-in $\mathrm{Ca}^{2+}$ sensitization of smooth muscle. Proc. Nat1. Acad. Sci. 93: 1340-1345.

Gopalbhai, K. and Meloche, S. 1998. Repression of mitogenactivated protein kinases ERK1/ERK2 activity by a protein tyrosine phosphatase in rat fibroblasts transformed by upstream oncoproteins. J. Cell. Physiol. 174: 35-47.

Graham, F.L. and Prevec, L. 1991. Gene transfer and expression protocols. In Manipulation of adenovirus vectors. Methods in molecular biology (ed. E.J. Murray), pp. 109-128. Humana Press, Clifton, NJ.

Grépin, C., Dagnino, L., Robitaille, L., Haberstroh, L., Antakly, T., and Nemer, M. 1994. A hormone-encoding gene identifies a pathway for cardiac but not skeletal muscle gene transcription. Mol. Cell. Biol. 14: 3115-3129.

Grépin, C., Nemer, G., and Nemer, M. 1997. Enhanced cardiogenesis in embryonic stem cells overexpressing the GATA-4 transcription factor. Development 124: 2387-2395.

Hall, A. 1998. Rho GTPases and the actin cytoskeleton. Science 279: 509-514.

Hasegawa, K., Lee, S.J., Jobe, S.M., Markham, B.E., and Kitsis, R.N. 1997. cis-acting sequences that mediate induction of beta-myosin heavy chain gene expression during left ventricular hypertrophy due to aortic constriction. Circulation 96: 3943-3953.

Hellman, U., Wernstedt, C., Gonez, J., and Heldin, C.H. 1995. Improvement of an 'in-gel' digestion procedure for the micropreparation of internal protein fragments for amino acid sequencing. Anal. Biochem. 224: 451-455.

Herzig, T.C., Jobe, S.M., Aoki, H., Molkentin, J.D., Cowley, Jr., A.W., Izumo, S., and Markham, B.E. 1997. Angiotensin II typela receptor gene expression in the heart: AP- 1 and GATA-4 participate in the response to pressure overload. Proc. Natl. Acad. Sci. 94: 7543-7548.

Hewick, R.M., Hunkapiller, M.W., Hood, L.E., and Dreyer, W.J. 1981. A gas-liquid solid phase peptide and protein sequenator. J. Biol. Chem. 256: 7990-7997.

Hill, C.S., Wynne, J., and Treisman, R. 1995. The Rho family GTPases RhoA, Rac1, and $\mathrm{CDC} 42 \mathrm{Hs}$ regulate transcriptional activation by SRF. Cell 81: 1159-1170.

Hirata, K., Kikuchi, A., Sasaki, T., Kuroda, S., Kaibuchi, K., Matsuura, Y., Seki, H., Saida, K., and Takai, Y. 1992. Involvement of rho p21 in the GTP-enhanced calcium ion sensitivity of smooth muscle contraction. J. Biol. Chem. 267: 87198722 .

Hoshijima, M., Sah, V.P., Wang, Y., Chien, K.R., and Brown, J.H. 1998. The low molecular weight GTPase Rho regulates myofibril formation and organization in neonatal rat ventricular 
myocytes. Involvement of Rho kinase. J. Biol. Chem. 273: $7725-7730$.

Hunter, J.J. and Chien, K.R. 1999. Signaling pathways for cardiac hypertrophy and failure. N. Engl. I. Med. 341: 12761283.

Ip, H.S., Wilson, D.B., Heikinheimo, M., Tang, Z., Ting, C.N., Simon, M.C., Leiden, J.M., and Parmacek, M.S. 1994. The GATA-4 transcription factor transactivates the cardiac muscle-specific troponin C promoter-enhancer in nonmuscle cells. Mol. Cell. Biol. 14: 7517-7526.

Kamisago, M., Sharma, S.D., DePalma, S.R., Solomon, S., Sharma, P., McDonough, B., Smoot, L., Mullen, M.P., Woolf, P.K., Wigle, E.D., et al. 2000. Mutations in sarcomere protein genes as a cause of dilated cardiomyopathy. N. Engl. J. Med. 343: $1688-1696$

Kimura, K., Ito, M., Amano, M., Chihara, K., Fukata, Y., Nakafuku, M., Yamamori, B., Feng, J., Nakano, T., Okawa, K., et al. 1996. Regulation of myosin phosphatase by Rho and Rhoassociated kinase (Rho-kinase). Science 273: 245-248.

Kuo, C.T. and Leiden, J.M. 1999. Transcriptional regulation of T lymphocyte development and function. Annu. Rev. Immunol. 17: 149-187.

Kuo, C.T., Morrisey, E.E., Anandappa, R., Sigrist, K., Lu, M.M., Parmacek, M.S., Soudais, C., and Leiden, J.M. 1997. GATA4 transcription factor is required for ventral morphogenesis and heart tube formation. Genes \& Dev. 11: 1048-1060.

Kureishi, Y., Kobayashi, S., Amano, M., Kimura, K., Kanaide, H., Nakano, T., Kaibuchi, K., and Ito, M. 1997. Rho-associated kinase directly induces smooth muscle contraction through myosin light chain phosphorylation. J. Biol. Chem. 272: 12257-12260.

Kuwahara, K., Saito, Y., Nakagawa, O., Kishimoto, I., Harada, M., Ogawa, E., Miyamoto, Y., Hamanaka, I., Kajiyama, N., Takahashi, N., et al. 1999. The effects of the selective ROCK inhibitor, Y27632, on ET-1-induced hpertrophic response in neonatal rat cardiac myocytes-possible involvement of Rho/ROCK pathway in cardiac muscle cell hypertrophy. FEBS Lett. 452: 314-318.

Liang, Q., De Windt, L.J., Witt, S.A., Kimball, T.R., Markham, B.E., and Molkentin, J.D. 2001. The transcription factors GATA4 and GATA6 regulate cardiomyocyte hypertrophy in vitro and in vivo. J. Biol. Chem. 276: 30245-30253.

Ludwig, S., Hoffmeyer, A., Goebeler, M., Kilian, K., Hafner, H., Neufeld, B., Han, J., and Rapp, U.R. 1998. The stress inducer arsenite activates mitogen-activated protein kinases extracellular signal-regulated kinases 1 and 2 via a MAPK kinase 6/p38-dependent pathway. J. Biol. Chem. 273: 1917-1922.

Magie, C.R., Meyer, M.R., Gorsuch, M.S., and Parkhurst, S.M. 1999. Mutations in the Rhol small GTPase disrupt morphogenesis and segmentation during early Drosophila development. Development 126: 5353-5364.

Marinissen, M.J., Chiariello, M., Pallante, M., and Gutkind, J.S. 1999. A network of mitogen-activated protein kinases links $\mathrm{G}$ protein-coupled receptors to the c-jun promoter: A role for c-Jun NH2-terminal kinase, p38s, and extracellular signalregulated kinase 5. Mol. Cell. Biol. 19: 4289-4301.

Marinissen, M.J., Chiariello, M., and Gutkind, J.S. 2001. Regulation of gene expression by the small GTPase Rho through the ERK6 (p38 gamma) MAP kinase pathway. Genes \& Dev. 15: $535-553$.

McBride, K. and Nemer, M. 1998. The C-terminal domain of c-fos is required for activation of an AP-1 site specific for jun-fos heterodimers. Mol. Cell. Biol. 18: 5073-5081.

Meloche, S., Landry, J., Huot, J., Houle, F., Marceau, F., and Giasson, E. 2000. p38 MAP kinase pathway regulates angiotensin II-induced contraction of rat vascular smooth muscle.
Am. J. Physiol. Heart Circ. Physiol. 279: H741-H751.

Minden, A., Lin, A., Claret, F.X., Abo, A., and Karin, M. 1995. Selective activation of the JNK signaling cascade and c-Jun transcriptional activity by the small GTPases Rac and Cdc42Hs. Cell 81: 1147-1157.

Molkentin, J.D. and Dorn II, G.W. 2001. Cytoplasmic signaling pathways that regulate cardiac hypertrophy. Annu. Rev. Physiol. 63: 391-426.

Molkentin, J.D., Kalvakolanu, D.V., and Markham, B.E. 1994. Transcription factor GATA-4 regulates cardiac muscle-specific expression of the $\alpha$-myosin heavy-chain gene. Mol. Cell. Biol. 14: 4947-4957.

Molkentin, J.D., Lin, Q., Duncan, S.A., and Olson, E.N. 1997. Requirement of the transcription factor GATA4 for heart tube formation and ventral morphogenesis. Genes \& Dev. 11: 1061-1072.

Morimoto, T., Hasegawa, K., Kaburagi, S., Kakita, T., Wada, H., Yanazume, T., and Sasayama, S. 2000. Phosphorylation of GATA-4 is involved in alpha 1-adrenergic agonist-responsive transcription of the endothelin-1 gene in cardiac myocytes. J. Biol. Chem. 275: 13721-13726.

Morin, S., Charron, F., Robitaille, L., and Nemer, M. 2000. GATA-dependent recruitment of MEF2 proteins to target promoters. EMBO J. 19: 2046-2055.

Morin, S., Paradis, P., Aries, A., and Nemer, M. 2001. Serum response factor-GATA ternary complex required for nuclear signaling by a G-protein-coupled receptor. Mol. Cell. Biol. 21: 1036-1044.

Murphy, A.M., Thompson, W.R., Peng, L.F., and Jones II, L. 1997. Regulation of the rat cardiac troponin I gene by the transcription factor GATA-4. Biochem. J. 322: 393-401.

Nemer, G., Qureshi, S.A., Malo, D., and Nemer, M. 1999. Functional analysis and chromosomal mapping of GATA5, a gene encoding a zinc finger DNA-binding protein. Mamm. Genome 10: 993-999.

Nemoto, S., Sheng, Z., and Lin, A. 1998. Opposing effects of Jun kinase and p38 mitogen-activated protein kinases on cardiomyocyte hypertrophy. Mol. Cell. Biol. 18: 3518-3526.

Perona, R., Montaner, S., Saniger, L., Sanchez-Perez, I., Bravo, R., and Lacal, J.C. 1997. Activation of the nuclear factor-кB by Rho, CDC42, and Rac-1 proteins. Genes \& Dev. 11: 463475.

Ren, X.D., Kiosses, W.B., and Schwartz, M.A. 1999. Regulation of the small GTP-binding protein Rho by cell adhesion and the cytoskeleton. EMBO J. 18: 578-585.

Renshaw, M.W., Toksoz, D., and Schwartz, M.A. 1996. Involvement of the small GTPase Rho in integrin-mediated activation of mitogen-activated protein kinase. I. Biol. Chem. 271: 21691-21694.

Sah, V.P., Hoshijima, M., Chien, K.R., and Brown, J.H. 1996. Rho is required for Galphaq and $\alpha 1$-adrenergic receptor signaling in cardiomyocytes. Dissociation of Ras and Rho pathways. J. Biol. Chem. 271: 31185-31190.

Sah, V.P., Minamisawa, S., Tam, S.P., Wu, T.H., Dorn, G.W., Ross, Jr., J., Chien, K.R., and Brown, J.H. 1999. Cardiac-specific overexpression of RhoA results in sinus and atrioventricular nodal dysfunction and contractile failure. J. Clin. Invest. 103: 1627-1634.

Sahai, E., Alberts, A.S., and Treisman, R. 1998. RhoA effector mutants reveal distinct effector pathways for cytoskeletal reorganization, SRF activation and transformation. EMBO $\mathrm{T}$. 17: 1350-1361.

Schwartz, M.A. and Shattil, S.J. 2000. Signaling networks linking integrins and rho family GTPases. Trends Biochem. Sci. 25: $388-391$.

Seidman, J.G. and Seidman, C. 2001. The genetic basis for car- 
diomyopathy: From mutation identification to mechanistic paradigms. Cell 104: 557-567.

Sepulveda, J.L., Belaguli, N., Nigam, V., Chen, C.Y., Nemer, M., and Schwartz, R.J. 1998. GATA-4 and Nkx-2.5 coactivate Nkx-2 DNA binding targets: Role for regulating early cardiac gene expression. Mol. Cell. Biol. 18: 3405-3415.

Sotiropoulos, A., Gineitis, D., Copeland, J., and Treisman, R. 1999. Signal-regulated activation of serum response factor is mediated by changes in actin dynamics. Cell 98: 159-169.

Suzuki, E., Evans, T., Lowry, J., Truong, L., Bell, D.W., Testa, J.R., and Walsh, K. 1996. The human GATA-6 gene: Structure, chromosomal location, and regulation of expression by tissue-specific and mitogen-responsive signals. Genomics 38: $283-290$.

Takano, H., Komuro, I., Oka, T., Shiojima, I., Hiroi, Y., Mizuno, T, and Yazaki, Y. 1998. The Rho family G proteins play a critical role in muscle differentiation. Mol. Cell. Biol. 18: $1580-1589$.

Takizawa, P.A., Sil, A., Swedlow, J.R., Herskowitz, I., and Vale, R.D. 1997. Actin-dependent localization of an RNA encoding a cell-fate determinant in yeast. Nature 389: 90-93.

Thorburn, J., Xu, S., and Thorburn, A. 1997. MAP kinase- and Rho-dependent signals interact to regulate gene expression but not actin morphology in cardiac muscle cells. EMBO $\mathrm{f}$. 16: $1888-1900$.

Tominaga, T., Sahai, E., Chardin, P., McCormick, F., Courtneidge, S.A, and Alberts, A.S. 2000. Diaphanous-related formins bridge Rho GTPase and Src tyrosine kinase signaling. Mol. Cell 5: 13-25.

Treisman, R., Alberts, A.S., and Sahai, E. 1998. Regulation of SRF activity by Rho family GTPases. Cold Spring Harb. Symp. Quant. Biol. 63: 643-651.

Uehata, M., Ishizaki, T., Satoh, H., Ono, T., Kawahara, T., Morishita, T., Tamakawa, H., Yamagami, K., Inui, J., Maekawa, M., et al. 1997. Calcium sensitization of smooth muscle mediated by a Rho-associated protein kinase in hypertension. Nature 389: 990-994.

Viger, R.S., Mertineit, C., Trasler, J.M., and Nemer, M. 1998. Transcription factor GATA-4 is expressed in a sexually dimorphic pattern during mouse gonadal development and is a potent activator of the Müllerian inhibiting substance promoter. Development 125: 2665-2675.

Wang, G.F., Nikovits, Jr., W., Schleinitz, M., and Stockdale, F.E. 1998. A positive GATA element and a negative vitamin D receptor-like element control atrial chamber-specific expression of a slow myosin heavy-chain gene during cardiac morphogenesis. Mol. Cell. Biol. 18: 6023-6034.

Wang, Y., Huang, S., Sah, V.P., Ross, J.J., Brown, J.H., Han, J., and Chien, K.R. 1998. Cardiac muscle cell hypertrophy and apoptosis induced by distinct members of the p38 mitogenactivated protein kinase family. I. Biol. Chem. 273: 21612168.

Watanabe, N., Kato, T., Fujita, A., Ishizaki, T., and Narumiya, S. 1999. Cooperation between mDial and ROCK in Rho-induced actin reorganization. Nat. Cell Biol. 1: 136-143.

Williams, K., Lopresti, M., and Stone, K. 1997. Internal protein sequencing of SDS-PAGE-separated proteins: Optimisation of an in gel digest protocol. In Techniques VIII (ed. D. Marshak), pp. 79-90. Academic Press, San Diego, CA.

Wunnenberg-Stapleton, K., Blitz, I.L., Hashimoto, C., and Cho, K.W. 1999. Involvement of the small GTPases XRhoA and XRnd 1 in cell adhesion and head formation in early Xenopus development. Development 126: 5339-5351.

Zechner, D., Thuerauf, D.J., Hanford, D.S., McDonough, P.M., and Glembotski, C.C. 1997. A role for the p38 mitogen-activated protein kinase pathway in myocardial cell growth, sarcomeric organization, and cardiac-specific gene expression. J. Cell Biol. 139: 115-127.

Zohar, M., Teramoto, H., Katz, B.Z., Yamada, K.M., and Gutkind, J.S. 1998. Effector domain mutants of Rho dissociate cytoskeletal changes from nuclear signaling and cellular transformation. Oncogene 17: 991-998. 


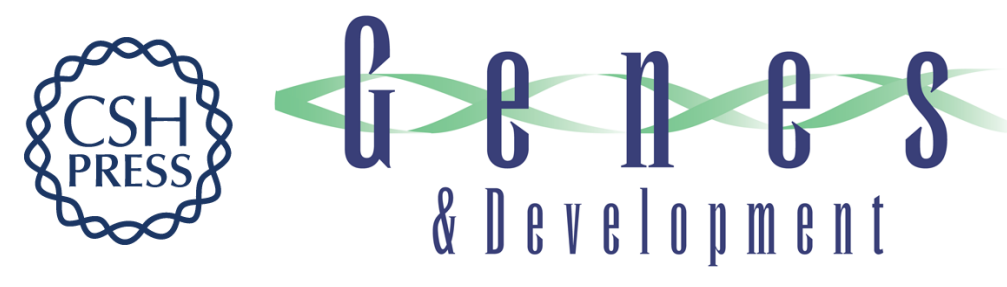

\section{Tissue-specific GATA factors are transcriptional effectors of the small GTPase RhoA}

Frédéric Charron, George Tsimiklis, Mathieu Arcand, et al.

Genes Dev. 2001, 15:

Access the most recent version at doi:10.1101/gad.915701

References This article cites 80 articles, 54 of which can be accessed free at:

http://genesdev.cshlp.org/content/15/20/2702.full.html\#ref-list-1

License

Email Alerting Receive free email alerts when new articles cite this article - sign up in the box at the top Service right corner of the article or click here.

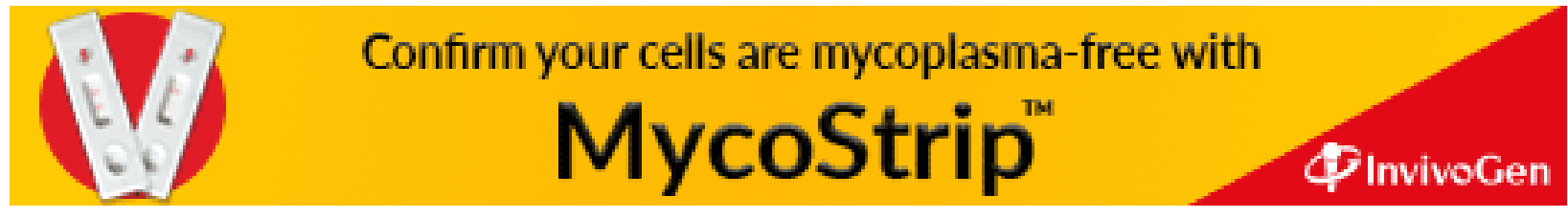

